\title{
Non-destructive testing and evaluation for structural integrity
}

\author{
BALDEV RAJ, T JAYAKUMAR and B P C RAO \\ Division for PIE \& NDT Development, Indira Gandhi Centre for Atomic \\ Research, Kalpakkam 603 102, India
}

\begin{abstract}
Reliable performance of a component or structure depends on pre-service quality of the component and in-service degradation of the component under operating conditions. The role of non-destructive evaluation (NDE) in ensuring pre-service quality and also monitoring in-service degradation to avoid premature failure of the components/structures is ever increasing. There are many NDE techniques based on various physical principles. The end objective of NDE is detection and characterisation of anomalies such as defects, stresses and microstructural degradations in materials. This is accomplished by establishing correlation between a nondestructively measured physical/derived parameter and quantitative information on defects/stresses/microstructures. The NDE information together with design parameters are taken into consideration for evaluation of integrity and life assessment of the components/structures. In this paper, a brief description of the physical concepts of NDE methods and the physical/derived parameters that are used for assessing defects, stresses and microstructures are given. A few case studies highlighting the importance of non-destructive testing and evaluation for structural integrity assessment are also discussed based on the investigations carried out at the authors' laborato:y. Emerging concepts like intelligent processing of materials, expert systems, neural networks, use of multisensors with fusion of data and exploitation of signal analysis and imaging approaches are also addressed in this paper.
\end{abstract}

Keywords. Non-destructive evaluation; structural integrity; life assessment; defects; stresses; microstructures.

\section{Introduction}

Assessment of integrity of engineering components and structures is becoming increasingly important for both economic and safety reasons. It is now widely accepted that all components and structures possess "defects" from the start of their service life (this forms an important and initial assumption in fracture mechanics) and that defect assessment is the way to control structural integrity reliably. Defects are those anomalies which when not removed or repaired might lead to ultimate loss of structural integrity of the material or component. Such defects include surface and 
sub-surface cracks, inclusions, pores, incompletely joined regions in welds or other joints and residual stresses, macro- or microstructural degradations etc. in metallic materials and delaminated or debonded regions, fibre fracture, matrix crazing etc. in composites. While surface defects are of immediate concern, due consideration is also to be given to sub-surface defects and other anomalies. In either case, it is important to understand the factors that govern the likely growth of defects/anomalies or cracks originating from them. In particular the size of the defect, its nature, its location, the stress to which it is subjected and the local properties of the material in which it is embedded, all play a major role in determining its rate of growth (Silk \& Whaphan 1989). According to fracture mechanics, defects present in materials lead to failure by growing to a critical, self-propagating size. The fracture mechanics concepts allow onc to calculate the critical sizes of defects as a function of their depth. length, active stress system and stress intensity and such properties of the material as its elastic modulus, yield strength and fracture toughness (David 1981). On the other hand, by knowing the dimensions of defects present in a component, it is possible to estimate both remaining life of the component and extent of degradation.

In the pre-service scenario, defects may be present at the raw material stage or might have been introduced during machining, fabrication, heat treatment and assembling. Similarly, defects may be generated due to deterioration of the material/component/ structure as a result of one or a combination of operating conditions like temperature, stress, chemical environment and irradiation leading to mechanisms such as creep, fatigue, stress corrosion, embrittlement etc. These mechanisms result in deterioration of mechanical properties, crack initiation and propagation, leaks in pressurised components and catastrophic failures. Hence, reliable performance of a component/structure depends on the pre-service quality and in-service degradation of the component under operating conditions. The pre-service quality can be achieved by good engineering practices i.e. by way of selecting suitable quality raw materials and ensuring that harmful defects are not produced during the subsequent stages of fabrication and assembly. In-service degradation of the component can be assessed by quantitative characterisation of anomalies such as defects, stresses and micro-structural degradations. Their early detection and assessment is essential to avoid damage and loss of structural integrity of components. In this regard, non-destructive evaluation (NDE) plays an important role for the reliable assessment of the anomalies by performing inspections at various stages. To give an example, the acoustic emission technique is used for detection of initation or propagation of any microcracks, and also any fluid leakage at inaccessible locations, by picking up signals from accessible locations. Using this technique, on-line monitoring of critical components and structures can give advance warning before occurrence of an accident or catastrophe due to material degradation under service conditions.

There are many non-destructive test (NDT) techniques based on various physical principles. The interaction of a medium (like electromagnetic radiation, sound waves) with various types of anomalies present in a material under study are used to quantitatively assess structural integrity. NDE procedures involve establishing correlations between non-destructively measured physical/derived parameters and quantitative information about anomalies. To give an example, eddy-current NDT involves measurement of change impedance and determination of its correlation with anomalies such as change in electrical conductivity or microstructure, or the presence of a crack. These correlations, together with design parameters and inputs from fracture mechanics, 
are taken into consideration for integrity and life assessment of the component. It should be emphasised that anomaly assessment information by NDE techniques is more meaningful when applied together with expertise from other related disciplines such as metallurgy, corrosion, fracture mechanics, stress analysis, design and operation. This approach enables evaluation of the degradation vis-a-vis performance and life prediction of components. Application of computers and robotics during inspection further enhances the sensitivity for defect detection. Though engineering structures are fabricated from metallic substances, as well as ceramics and composites, the discussions in this paper essentially pertain to integrity monitoring of structures of metallic origin.

There has been a continuous and ever-increasing demand from the industry for the NDE professionals in developing new techniques and procedures to achieve the "minimum defect component with maximum confidence and reliability" goal. There has been a tremendous effort put in worldwide to meet this challenge and encouraging results have been obtained. For example, due to fracture mechanics considerations, it is required to detect defects smaller than 100 microns in structures, made of engineering ceramics. This requirement calls for development, implementation and application of high resolution and high sensitivity techniques. High frequency ultrasonics and microtomography are the two recently evolved techniques to meet the above demands. At the same time, industry is more conscious of utilising the benefits of NDE towards better performance and extension of life of various components/structures.

The knowledge of microstructural variations in a component is also very important to ensure the desired performance. Traditionally, microstructures are investigated by microscopic methods which are destructive in nature. At the authors' laboratory pioneering work has been done to adopt NDE techniques for the investigation of microstructural degradations. These techniques are useful for damage assessment, life estimation and extension applications of ageing plants and components, in particular, for continued service of components subjected to unacceptable service conditions during system malfunction or under accidental conditions.

In addition to the information about defects and microstructures, knowledge of residual stresses in a component is a!so essential for reliable assessment of structural integrity. Residual stresses are the system of stresses which exist in a material or component when it is free from external loads. The maximum value to which the residual stress can reach in a material is its elastic limit. Manufacturing processes are the most common causes of residual stress. In some instances, residual stress may also be induced later in the life of the structure during installation, or assembly or operation. Another common cause of residual stress is in-service repair or modification. Among the three types of residual stresses viz. macroscopic, microscopic and sub-microscopic, macriscopic residual stresses are important. They are generally caused by inhomogenous plastic strains in a structure. During welding, plastic deformation is introduced mainly by thermal stresses due to large temperature gradients present at various stages of the welding process. Most of the engineering applications and fracture mechanics calculations require the knowledge of residual stresses of this type only. Again in this type, tensile residual stresses are generally detrimental, increasing the susceptibility of a component to failures due to such causes as fatigue and stress corrosion. Compressive residual stresses are usually beneficial, tending to reduce the above susceptibilities. Thus residual compressive stresses are often deliberately created on the surface. The role of NDE in detecting and assessing residual stresses is ever increasing and today well established techniques/procedures exist in this regard. 
In this paper, a brief description of the physical concepts of various NDT inethods and the physical/derived parameters which are used for assessing the above mentioned anomalies, namely defects/stresses/microstructure, are given. A few case studies highlighting the importance of non-destructive testing and evaluation for structural integrity assessment are discussed. In many cases, the investigations carried out at the authors' laboratory are given as examples. This paper also gives an account of the emerging concepts like expert systems, imaging, robotics, intelligent processing of materials, fusion of NDT data and signal analysis approaches that are responsible for enhanced reliability in NDE. Finally, the paper also brings out various research and development activities carried out at the authors' laboratory leading to new techniques and procedures.

\section{NDE techniques for structural integrity monitoring}

The main aim of NDE is to detect and characterise anomalies that can adversely affect the performance of the component under test without impairing its intended service. NDE implies complete responsibility to assess the seriousness of a situation realistically in order to enable the management to make the right decisions. Thus, NDE is testing, evaluation and responsibility. This almost always implies something more than the mere detection of defects. It is now widely accepted that locations where residual stresses and microstructural degradations exist are potential sites for the origin of defects. Hence, NDE involves detection and characterisation of defects, stresses and microstructural degradations. Their early detection is essential to avoid damage and loss of structural integrity of components. In this regard, the role of NDE is ever increasing to ensure reliability of performance in both pre-service and in-service stages.

Usually, to properly assess defect severity, one needs to know the type of defect, its location, approximate size, shape and orientation. NDT techniques available for the assessment of integrity of structures/components prior to, during and after their installation, are many. Some of the widely used techniques include visual examination, liquid penetrant testing, leak testing, vibration monitoring, magnetic particle inspection, utrasonic testing, eddy current testing, gamma and $\mathrm{X}$-radiography, acoustic emission, tomography, magnetic flux leakage method, laser holography and interferometry, infrared thermography etc. Broadly, these techniques can be classified into two categories, depending on the nature of inspection capability, viz. static and dynamic techniques. While static techniques can be used to detect cracks in materials off-line, dynamic techniques are used for on-line monitoring. Two widely used dynamic NDT techniques are acoustic emission and infrared thermography. All other techniques mentioned above come under the category of static techniques.

Since the interrogating field and the interactions are different, the minimum detectable defect sizes are different in different NDT techniques and mainly depend on the instrumentation. Consistency and repeatability of measured parameters have to be ensured. While selecting an NDT technique for a specific application, not only the minimum detectable defect size, but also the probability and the confidence level of detection are to be considered. Most NDT techniques have a wide range of applications and capabilities and comparison of data is valid only for a particular application, a specific type of defect and a particular material. For example, for detection of fatigue cracks in light-alloy panels, it is not surprising that eddy current and penetrant testing 
are superior to ultrasonic testing and radiography. Hence, choice of the NDT technique depends on factors such as applicability, accessibility and suitability based on analysis and past experience. It may sometimes be necessary to use a combination of two or more techniques, in the best complementary way, to carrv out complete and reliable inspection. Information about material composition, properties, micro-structure, fabrication procedure and environment is essential to identify the potential sites for origin of defects, their nature, probable size and orientation. All the above mentioned details would aid in selecting a suitable combination of techniques. In this regard, detailed mock-up studies are essential prior to actual inspection, to optimise equipment parameters, design and selection of sensors, selection of standard defects, operating conditions and procedure for recording and evaluation of NDT data to arrive at the desired sensitivity and reliability. Reliability is also ensured by following procedures as per codes and standards. A more recent concept in this direction is fusion of NDT data, which attempts to create a global picture of the fitness for purpose of the inspected zones. It involves combining data from more than one NDT method and displaying of a 3-D visual of the anomaly. In other words, if the "shadow" information from a radiograph is combined with depth information from an ultrasonic shear wave probe and surface breaking information from magnetic particle inspection, then the NDE personnel can provide a comprehensive description of the defect. This information can be presented and manipulated in a 3-D graphical format, making it much easier for a non-specialist to interpret the results of inspection in a reliable manner (Edwards et al 1993).

It is now well established from fracture mechanics considerations that planar defects (cracks, lack of fusion etc.) are more serious than volumetric defects (porosity, gas holes, round inclusions etc.) from the loss of strength point view. It is now clear that the depth or height of defect is more detrimental than its length and also surface breaking defects are more harmful than totally internal defects. A consequence of these findings is the changes in the acceptance levels for different types of defects.

For pre-service inspection, a definite requirement exists for more accurate NDT techniques which could be applied with the aim of producing a structure with no flaws greater than a predetermined size which can be as small as the defect detectable by NDT methods. Advancements in the fields of electronics and computer sciences, development of new methodologies, better understanding of interaction between the interrogating media and materials and new challenging requirements are pushing the NDE technology to achieve significant progress. A major spin-off in the recent past in this direction is "intelligent processing of materıals". This concept ensures $100 \%$ acceptability of raw materials and fabricated components by providing feedback to the manufacturing/fabrication processes about the presence/occurrence of defects on-line thus allowing for immediate corrective action (Baldev Raj 1994b).

Imaging techniques show a promise towards enhanced detection and characterisation of defects in components. It has often been said that an NDE image is worth a thousand NDE signals. NDE personnel feel more confortable in interpreting images than analysing signals. Imaging can be done with many different media, including optical, inirared, X-ray, gamma-ray, ultrasound, eddy current, thermal wave, magnetic resonance etc. Thus, there is a broad spectrum of techniques from which selection can be made. Infrared imaging, ultrasonic C-scan imaging, scanning acoustic microscopy, scanning laser acoustic microscopy, computer aided tomography and eddy current imaging are some of the techniques currently being used worldwide for wide-ranging 
applications. The imaging format provides a global perspective of the inspected region and allows a balanced interpretation. Also, imaging techniques have the potential of automating the measurement process, providing estimates of defect size from the image data, producing accurate characterisation of cracks and improving the probability of detection (Baldev Raj 1993a).

The latest state of the art in NDE is the development of expert systems. Expert systems are interactive computer programs which attempt to simulate the expert's thought processes and provide a wide range of advice. An unusual feature of these systerns in comparison with more traditional algorithmic programs is the ability to handle heuristics, or rules-of-thumb. This feature makes the expert system an attractive tool for evaluation of NDT data and failure analysis. The use of robotic devices for reliable NDE of components is assuming great importance in many applications like the nuclear, space and chemical industries especially when there is a need for high probability of defect detection, reduction in radiation exposure to NDE personnel and limiting the operator dependency. Manipulators based on robotic principles have come into existence and the demand for manipulators with computerised data acquisition, processing and evaluation is growing faster for pre-service and in-service inspections (Baldev Raj 1992).

In the following sections, the principles, capabilities and applications of some of the widely used NDE techniques for the assessment of structural integrity are discussed. Special emphasis has been laid on discussing the physical principles of NDT techniques and the interaction of the interrogating medium/field with the anomalies that affect structural integrity. Besides an attempt has been made to briefly discuss the recent trends in various techniques.

\subsection{Visual inspection}

Visual inspection (VI) constitutes an important and widely used NDE method for structural integrity evaluation. VI is a very valuable method for the evaluation of discontinuities open to the surface. However, it is not suitable for detecting subsurface and interior discontinuities. VI is a relatively simple and effective technique that is complete without detailed analysis of data/signals/patterns like other NDT techniques. In VI, an NDE inspector arrives at an immediate decision solely on what he observes during inspection. Capabilities of VI can be enhanced considerably by using simple aids such as magnifying glass, microscopes etc. for viewing, dimensional measurements etc. The advances in the area of optics have had far-reaching consequences in the field of visual inspection. Industrial telescopes, usually known as borescopes or introscopes enable inspection of inaccessible surfaces. They are best known for in-situ examination of inner surfaces of tubes/piping and also for the inspection of surfaces of turbine blades in aero-engines for the detection of cracks and corrosion without needing dismantling (Halmshaw 1989). The advent of fibroscopes with rotating headshas increased the versatility of visual inspection. With significant advances in display, storage and handling of images, it is now possible to record the information permanently and to carry out detailed investigations referring to the records of prior inspections to determine whether there has been crack growth, formation of additional cracks, or other progressive changes. The use of image processing techniques greatly enhances the sensitivity of defect detection and helps in obtaining reliable information about their dimensional measurements. 


\subsection{Liquid penetrant inspection}

Liquid penetrant inspection (LPI) is another widely used NDE method for the detection of discontinuities open to the surface in any material/component which has a non- absorbant surface, irrespective of the component geometry and its material properties. LPI utilises the natural accumulation of a fluid, called penetrant, around a disconti-nuity to create a recognisable indication of a crack or other surface opening. A typical example to understand the principle involved in LPI is the ready visibility of cracks in concrete structures after a rain. $\mathrm{LPl}$ is directly concerned with the behaviour of fluids on surface (Halmshaw 1989). Surface tension and capillary are the two areas of fluid mechanics relevant to LPI. Surface tension is the property that affects the flow of the fluid on the surface to be inspected. Capillary forces drive the penetrant along the material surface into the surface openings and, finally out of them and into the developer. In brief, in LPI a liquid is applied to the surface of the component for a certain predetermined time (dwell time) during which the penetrant seeps through the surface discontinuity. After this, the excess penetrant is removed from the surface. The surface is then dried and a developer is applied to it. The penetrant that remains in the discontinuity is absorbed by the developer indicating the presence as well as the location, size and nature of the discontinuity. Optical recognition exploiting the full range of light spectrum from visible to ultravoilet light, is used for the defect detection in $\mathrm{LPI}$.

The LPI processes are typically classified by the indicating method i.e. visible or fluorescent dye and the method used to remove the excess penetrant from the component surface. The three widely adopted LPI systems are water-washable, post-emulsifiable and solvent removable. Fluorescent dye penetrants have high sensitivity and are particularly useful for detecting cracks of small widths (down to 0.5 microns). The increased sensitivity is due to the absence of any visible background (either white or coloured) layer covering the area under inspection which would otherwise absorb a part of the incident light. LPI technique is very useful for detection of fatigue cracks, stress corrosion cracks and other service-induced defects open to the surface. The absence of a volumetric interrogating medium in LPI restricts the technique to detect variations/abnormalities open to the surface. Microstructure and stresses in the components cannot be assessed by LPI.

\subsection{Magnetic methods}

Magnetic methods of NDE are among the oldest and most pervasive because of the dominant production and use of steel and related ferromagnetic materials in the industry. When a ferromagnetic component is magnetised, the magnetic lines of force (the magnetic flux) are predominantly inside the material. However when there is a surface breaking or a sub-surface discontinuity, the field is distorted, causing local magnetic flux leakage fields. Effectively, the disconinuity causes a sudden localised change in magnetic permeability. These leakage fields are monitored/detected/recorded either by sprinkling finely divided ferromagnetic powders or by using sensors and the information on the location, shape and extent of the discontinuity producing the leakage field is obtained (Mix 1987). On the basis of recording and evaluation of the leakage fields, the magnetic methods can be classified into magnetic particle inspection 
(MPI) and magnetic leakage flux (MLF) and magnetic Barkhausen Noise (MBN) techniques. Because of the added advantage of these techniques over LPI in detecting subsurface defects, it is logical to specify magnetic methods for the structural integrity evaluation of all ferromagnetic materials. After the inspection by magnetic methods, it is necessary to subject the component to demagnetisastion, an act of reducing the flux density level in the component to a level at which its external field does not cause problems in service such as (a) wear due to pick-up of ferromagnetic parts in the case of rotating components, (b) arc deflection during welding and (c) interference effect on nearby instruments etc.

MPI consists of magnetisation of the component, application of magnetic powder and examination of powder patterns. The indications of defects are preserved by photography or video recording or by the use of peel-off transparent adhesive films. To obtain higher sensitivity for defect detection, fluorescent magnetic particles suspended in oil or kerosene are employed rather than the dry powders. Magnetic silicone rubber containing magnetic particles in suspension are widely used for the inspection of relatively inaccessible regions e.g. bolt holes and internal threads. These areas are of great concern in military aircraft and detection of cracks in these regions is challenging. In this method, a highly viscous rubber solution is applied on the component surface before magnetisation. After magnetisation, sufficient time is allowed for the particles to migrate to the leakage fields before the solution is cured. This method is also known as magnetic rubber inspection (Zheng \& Zhu 1993).

One major limitation of MPI is the necessity for application of magnetic field in different directions. This is because of the fact that the leakage field, and in turn the sensitivity in MPI, is maximum only when a defect is perpendicular to the direction of the magnetic field. Hence, in order to detect defects in different orientations, the magnetic field has to be applied in more than one direction. There are a wide variety of methods to magnetise a component such as prod, head shot, central conductor, yoke, cable etc. These methods essentially aim at producing circular and/or longitudinal magnetisation in the component. The method selected depends on such factors as the geometry of the component, desired direction of magnetic field, the expected orientation of defects and whether or not the defects are subsurface. Both AC and DC methods can be used. Because of the skin depth effect, $\mathrm{AC}$ methods are restricted to the detection of near-surface defects and therefore are not very effective for detection of subsurface cracks.

Procedures based on wet fluorescent MPI techniques have been successfully developed at the authors' laboratory for the structural integrity evaluation of $235 \mathrm{MW}$ low pressure turbine rotors of PHWRs (Baldev Raj 1993b). This effort consisted of performing MPI on turbine blades of all five stages and fir-tree root regions of all stages adopting cable and yoke methods of magnetisation respectively. Current ratings and sensitivity were optimised with the help of field indicators and gauss meters. These procedures have also been successfully used to perform MPI in-situ without lifting the rotor from the turbine bed. Defects detected by these procedures were characterised using direct current potential drop technique (refer $\$ 2.8$ below). Detailed in-situ metallography and residual stress measurements (X-ray diffraction technique) were carried out to supplement the MPI observations and to assess the damage at those regions. In-situ metallography involves polishing, etching, examination of the suspected regions with a portable microscope and recording of indications by the replication method. 
In MLF method, the presence and extent of defects is detected by monitoring the surface for localised fluctuations in the magnetic field with sensors like inductive coils, Hall probes, magnetometers and magnetoresistive, magnetic resonance and magnetographic type probes (Forster 1977). As in MPI, in this technique also, two forms of magnetisation i.e. DC and $A C$ are commonly used. The AC method has higher detection sensitivity than the DC method and defect signals are proportional to the depth of the defect. Since magnetisation is local, demagnetisation is not required. However, DC method is capable of detecting sub-surface defects and is relatively insensitive to interference from the material surface noise caused by roughness, scale etc. (Junger \& Brock 1990).

The higher sensitivity of the flux leakage methods (close to that of magnetic particle inspection) and the additional advantage of automatic evaluation without a human inspector makes the technique amenable to on-line inspection at the shop floor. AC MFL technique is used to characterise stresses in high strength steels and their welds. One of the primary application areas for practical MLF systems is that of axisymmetric components i.e. tubes, pipes, rods, bars, rounds, billets etc. Components of these geometries are particularly amenable to fully automated and relatively high speed scanning in a production line during their manufacture. MLF method is also widely accepted for in-service inspection of underground pipes in petrochemical industries (Collins et al 1984). This method has been successfully applied for the detection and assessment of defects in highly irregular component such as helicopter rotor blade D-spars, gear teeth, artillery projectiles etc. Another successful application is the inspection of rolling element anti-friction bearings which form critical components in gas turbine engines. high performance aircraft, helicopters, rocket engines, satellites etc. (Beissner et al 1980). Advances in sensor technology and data acquisition and analysis have resulted in realisation of fully automated MLF inspection method. More recently, Finite Element (FE) computer programs are being used to simulate this method for both simple and complex crack/component configurations. For defects such as fatigue cracks where there is evidence of a variable permeability effects, FE modelling provides an opportunity of realistic method of analysis (University Communique 1987).

Magnetic methods are potential methods for evaluation of microstructural degradations. Magnetic flux pertubation and acoustic emissions are generated when an induced magnetic field in ferromagnetic materials is swept in a hysteresis loop. The former is referred to as Magnetic Barkhausen Noise (MBN) and the latter is called Acoustic Barkhausen Noise (ABN). MBN signals are produced as a result of discrete changes in magnetisation caused mainly by the motion of the 180 domain walls as the magnetic field is varied. The signals are detected by a search coil. Similarly ABN signals are generated during the hysteresis sweep duc to the rotation of the $90^{\circ}$ domain walls and the associated magnetostriction. Since $M B N$ is related to the nucleation and movement of magnetic domain walls and their interactions with various microstructural features such as grain boundaries, precipitates, stresses etc. this technique is found to be useful for several applications including microstructural characterisation, characterisation of post-weld heat treatment in the weld joints and the measurement of residual stresses. Significant work has been done at the authors' laboratory in this direction (Bhattacharya 1994). In the case of 17-4 PH steel, MBN technique has been employed to identify the stages i.e. (i) build up of coherency strains, (ii) loss of coherency and (iii) interlath austenitic formation which otherwise need transmission electron microscopy and field ion microscopy investigations (Bhattacharya et al 1992b). In the 
case of $2 \cdot 25 \mathrm{Cr}-1 \mathrm{Mo}$ steel, precipitation of $\mathrm{Mo}_{2} \mathrm{C}$ could be identified using the MBN technique. Recrystallisation from martensite structure leading to ferrite formation in addition to coarse carbide precipitation could also be characterised. In $9 \mathrm{Cr}-1 \mathrm{Mo}$ steel, the incipient occurrence of delta ferrite could be detected by magnetic techniques. Even by transmission electron microscopy, it is difficult to identify the incipient occurrence. MBN technique has been successfully used for the characterisation of post-weld heat treatment in the weld joints of steam generator modules of the proposed Prototype Fast Breeder Reactor. These studies efficiently brought out the adaptability of MBN analysis for quality assurance of welds. ABN technique has been used for assessment of residual stresses in weld joints of structural steels (Bhattacharya et al 1992a). The rms voltage of the $A B N$ signal has been used as a parameter for studying the influence of stress relief annealing on the stress distribution. Increase in the rms voltage of the ABN signal corresponding to the decrease in the residual stresses could be observed. In the as-welded condition, stresses are higher at the centre of the weld region and decrease gradually at the regions away from it. Reduction in stresses due to annealing could be identified in the form of increase in $\mathrm{ABN}$ signal. The utilisation of magnetic parameters derived from hysteresis loop measurement and $\mathrm{MBN}$ and $\mathrm{ABN}$ signals for assessment of microstructures is emerging as a very promising technique for structural integrity monitoring.

\subsection{Radiographic techniques}

Radiographic techniques (RT) are effective industrial methods for the NDE of components/structures. Radiographic techniques use a beam of penetrating radiation such as $\mathrm{X}$-rays or gamma rays or atomic particles such as neutrons, protons and electrons (Baldev Raj \& Venkatraman 1989). When the beam passes through a component, some of the radiation energy is absorbed and the intensity of the beam is reduced. Variations in beam intensity are recorded on a film or fluoroscopic screen with digital system coupled with video monitors, and are seen as difference in shading typical of the type and size of any defect present. When the defect is an absence of material such as void or porosity, the image will appear darker than the surroundings. On the other hand, when the material in the defect is more absorptive than the surrounding material, the image will be lighter in appearance. In other words, the density of defect indications on the film or other recording media mentioned above, is inversely related to the total linear density of the material in the beam path. Decreased densities in the appearances of the indications on the radiographs will therefore indicate more dense material along the total beam path. Hence, porosity i.e., gas hole in the material, would appear on the radiograph as a spot or a field of spots darker than the surrounding material and foreign inclusions would appear as either darker or lighter spots depending on the density of the foreign material relative to the component (Bray \& Stanley 1989b). Corrosion is readily detected using radiography, since material loss affects the exposure of the film. The detectability of discontinuities by radiography is highly dependent on the shape and orientation of the anomaly as well as on the density. Microstructural degradations are difficult to detect by $\mathrm{X}$ or gamma radiography. However, neutron radiography can be used for metallurgical examination of irradiated materials with limited success.

While X-ray tubes, van de Graaff generators, betatrons, linear electron accelerators (LINACS) and microtons form sources for X-rays, radioisotopes like cobalt-60, 
iridium-192, caesium-137, thulium-170 and ytterbium-169 are used as typical gamma ray sources. Recent advances in X-ray tube technology have resulted in focal spots which are an order of magnitude smaller, thus giving rise to a whole new classification of microfocus radiography techniques (Peugeot 1982). It is thus possible to detect minute defects in thin components, thin welds of steel, aluminium or titanium alloys which was not possible earlier using conventional radiography. The most impressive feature of the microfocus X-ray source is its ability to produce extremely sharp radiographs at exceedingly short film-to-focus distances (Halmshaw 1989). In X-ray tubes, a small focal spot size of about 10 microns could be realised by electromagnetic and electrostatic focusing techniques of the electron beam. An outstanding example that brings out this capability is the work carried out at the authors' laboratory on the radiography of tube-to-tube sheet welds in $2.25 \mathrm{Cr}-1$ Mo steel tubes of steam generators of Prototype Fast Breeder Test Reactor (PFBR). Using rod anodes with true radial panoramic emission, full circumferential radiographs can be obtained at around $80 \mathrm{kV}$ in less than one minute on a Agfa D2 film with a sensitivity better than $1 \%$. This sensitivity is much better than that can be obtained with the best radio-isotope based technique (Venkatraman et al 1993c). The advent of X-ray image intensifiers has resulted in replacing the conventional fluoroscopy system to a real time radiography system. X-ray radiography is an important post-irradiation examination technique for the evaluation of nuclear fuel elements. This application is, however, beset with a problem called gamma fogging (exposing of film to gamma rays coming from fuel) which makes the interpretation of the radiographs difficult if not impossible. Successful procedures utilising post radiography image processing methods have been developed at the authors' laboratory to minimise gamma fogging.

Radiography with thermal neutrons (energies between 0.01 and $0.3 \mathrm{eV}$ ) has emerged as a powerful NDT technique, called Neutron Radiography (NR), for examination of nuclear materials and many other non-nuclear applications as well. Thermal neutrons have some properties which make them especially interesting for radiography. While the attenuation of X-rays in materials increases with atomic number in an orderly manner, the mass absorption co-efficients of elements for thermal neutrons appear almost random since neutron absorption does not depend on the electronic structure of the atom, but on the interaction with the atomic nucleus. Hence, $\mathrm{X}$-rays are stopped by dense materials and passed by light materials and in many instances neutrons have the reverse quality. For example, neutrons will penetrate the body of a large metal valve to give a good image of an internal rubber seal while $X$-rays will give the defects present in the metallic portion. It is now widely accepted that $X$-radiography and neutron radiography are complimentary to each other (Baldev Raj 1994a). NR is used in the metallurgical examination of irradiated fuel sub-assemblies, fuel pins and control rods. Also it can reveal information about movement of fuel pellets in fuel pin, dimensional changes of pins and pellets, pin to pin spacing, and plutonium distribution in the pellets. In aerospace industries NR has been used for inspecting the presence of solidified oil and grease in lubrication holes and passages. NR has been used to detect earlier stages of corrosion in aircraft structures that cannot be found with X-radiography. Other applications of NR include, inspection of rubber seals, plastics insulations, capacitors, potting of transformers, explosives and turbine blades made by investment casting and archaeological structures etc. At the authors' laboratory, a $30 \mathrm{~kW}$ uranium 233 fuelled swimming pool type reactor called Kalpakkam Mini (KAMINI) is nearing completion. The flux at the core is expected to be around $10^{13} \mathrm{n} / \mathrm{cm}^{2} / \mathrm{s}$ and the flux at the 
radiographic site would be $3 \times 10^{6}$ to $10^{7} \mathrm{n} / \mathrm{cm}^{2} / \mathrm{s}$. Two beam tubes are available for radiographic purposes, one for active sample radiography and the other for non-active sample radiography. Special gadgetry has been designed indigenously for precise positioning/rotation of components in front of neutron beam, remote controlled cassette drive mechanism and for carrying out real time imaging. A resolution of the order of 30 to 40 microns is expected (Kasiviswanathan et al 1989).

The major constraints of conventional radiography include (a) inability to accurately reveal the depth and height of defects so important for the structural integrity assessment by means of fracture mechanics, (b) poor discrimination of changes in density of an object being detected, and (c) confusion caused due to two-dimensional image of three-dimensional component. These limitations are overcome by Computeraided Tomography (CT) which is an useful concept for NDE. In CT, the transmission of radiation beams (X-ray, gamma-ray or neutron) through an object in a single plane is measured under various object angles and positions. From the transmitted inten- sities for many beam orientations, a CT image representing a map of absorption coefficients in the measured cross-sections is calculated and presented in visual form on a video display using a graphic system and colour-coded scales that represent various densities as different colours (Vontz et al 1988). Cracks, pores and density fluctuations in the material can be displayed by a change of colour. CT can be obtained in a digital form and can be further mathematically processed to extract the required information (Halmshaw 1989). A typical interesting application of CT is the assessment of engineering ceramics. Engineering ceramics have a number of excellent properties, in particular, high strength at elevated temperatures and oxidation resistance, which make them attractive materials for a variety of applications. On the other hand, the monolithic ceramics are very brittle (i.e. they possess very low fracture toughness), and the permitted defect is as small as 20 microns in certain applications. CT has been applied to the examination of advanced ceramics and has proven to be a very efficient method within the required detection limits (Arnold 1990). While gamma and X-ray are used for general applications the former is preferred for the inspection of thicker components. Neutrons are also being used for CT especially for the evaluation of nuclear fuel sub-assemblies and fuel pellets.

The latest state-of-the-art is development of expert systems using artificial intelligence for radiography. Efforts are underway at the authors' laboratory to develop an expert system for optimisation of procedure for radiography (Venkatraman et al 1993b).

\subsection{Ultrasonic testing}

Ultrasonic testing (UT) uses sound waves having frequencies usually in the mega cycle range. A sound wave travelling through a material will lose energy when it encounters an anomaly. This is manifested by a loss in pulse amplitude as well as a change in its appearance. There are three basic processes that account for loss of pulse energy, namely beam spreading, absorption and scattering. Beam spreading is primarily a geometric function where the intensity decreases with the square of the distance travelled. Absorption accounts for the mechanical energy converted to heat energy as the wave propagates. Scattering results from reflection at grain boundaries, small cracks and other anomalies. This phenomenon is utilised to non-destructively measure grain size in materials (Bray \& Stanley 1989a). 
Two basic methods in UT are pulse-echo and through transmission. While the former method makes use of a single transducer, the latter makes use of two. In the pulse-echo method, a transducer made of piezoelectric material (also called probe) transmits a pulse of mechanical energy into the component. The energy passes into the material, reflects from the back surface, and is detected by the same transducer, yielding a signal on an oscilloscope with a time-base. The oscilloscope would normally show the original pulse of the ultrasonic transducer (front surface echo), the back reflection and any extra blip indicating a reflection from a defect in the material. From the oscilloscope timing, the depth of the defect below the surface can be determined. Alternatively, in the transmission method, transducers are placed onopposite sides of the component and any reduced intensity sensed by the receiving transducer indicates the defect shadowing part of the ultrasonic radiation. The location of the defect cannot be obtained. Both pulse-echo reflection and transmission methods are in use and their selection depends on the accessible surface of the component. UT can detect defects oriented both in the plane of and normal to the surface of components using normal beam or angle beam transducers. By suitable design of ultrasonic transducer, ultrasonic beams can be introduced into a material at almost any angle. There are several forms of ultrasonic waves, the most widely used in NDT being compressional (longitudinal) and transverse (shear) waves. In a specific application of tube testing for detecting defects normal to the wall, the beam is converted to a shear wave which is propagated around the circumference or along the axis. In order to detect defects efficiently by UT, it is necessary to make the wavelength comparable to the expected defect size. Hence, for detection and assessment of smaller defects, it is necessary to use high frequency. The UT data can be displayed in three modes viz. A-scan, B-scan and C-scan (Szilard 1982; Baldev Raj et al 1994a).

Ultrasonic attenuation can be used to monitor material properties. Empirical correlations have been obtained between ultrasonic attenuation and the impact strength, fracture toughness, grain size and tensile strength of steels. Similarly, ultrasonic velocity measurements can be used to measure residual stresses in materials. This methodology uses shear waves polarised in two mutually perpendicular directions. These waves have slightly different velocities and so interfere, so that as the transducer is rotated, the interference vanishes when the polarising planes are parallel and perpendicular to the stress axis. Once this axis is known, the actual stress can be computed from the velocities (Halmshaw 1989). Stress measurements using ultrasonic technique are also dependent on the acousto-elastic effect i.e. strain-induced ultrasonic wave velocity variations in materials. By precise measurement of ultrasonic velocity, information about stress can be obtained. Using pulse-echo overlap method, accuracy of transit time measurements of the order of \pm 1 nano second have been achieved by us (Palanichamy et al 1992a).

Ultrasonic methods are also widely used for detection and characterisation of defects in structural welds (Pelseneer \& Louis 1974). We have developed procedures for reliable and automated detection of defects down to $5 \%$ wall thickness in the end cap weld joints of thin-walled fuel elements of PHWRs (Subramanian et al 1991). In view of the difficulties encountered during conventional UT due to upsets produced during welding process, easily implementable signal analysis approaches have been used (Baldev Raj et al 1992). High sensitivity defect detection and characterisation in weldments of maraging steels used for rocket motor casings in the aerospace industry is of great importance. Tight cracks $(3 \mathrm{~mm} \times 1 \mathrm{~mm})$ produced in these welds by fatigue 
loadings were detected by us using cluster and pattern analysis of UT data. Detection of such small defects enhances the payload capacity of the rocket (Kalyanasundaram et al 1991a).

Austenitic stainless steel (AUSS) components and structures find extensive applications in various industries and they enjoy a dominant position (75\% approximately) among other stainless steels. This is chiefly because of high level of fabricability and corrosion resistance. UT is the most widely used NDE technique for the assessment of AUSS and their welds. UT of AUSS welds and castings is much more difficult than that of other stainless steels because of the following: (a) severe attenuation at high frequencies, (b) presence of anisotropic grain structure (dendrites) which cause the ultrasonic beam to bend (beam skewing), and (c) noisy behaviour of the material masking the pulses from defects (Juva \& Haarvisto 1977). A whole range of new UT methodologies have been investigated in order to improve the UT inspection of AUSS welds and castings. Some of them include ultrasonic spectroscopy, acoustic holography and SAFT etc. Automated systems are now available for the inspection of pipe welds in critical components in nuclear, oil and other industries with limited access. An integrated prototype rule based expert system (ES) which helps in taking quick and :eliable decisions in the UT procedures to be adopted for efficient NDE of AUSS welds has been developed at the authors' laboratory (Rajagopalan et al 1992). This ES considers the following details before making a decision: dendritic microstructure of the weld, weld dimensions, geometry, joint type, welding procedure, metallurgical history, reflective characteristics of various types of defects, equipment parameters etc. Inspection of inaccessible regions and complex geometries would become simpler if the ultrasonic beam path is known. Visualisation of software for simulating the path taken by an acoustic/ultrasonic wave inside the weld is currently under development at the authors' laboratory.

A wide variety of conventional UT methods are available to measure crack depth like (i) defect echo height method, (ii) decibel drop method, (iii) edge echo method, (iv) scattering method and (v) composite aperture method. However, characterisation and sizing of defects requires sophisticated instrumentation, methodologies and computer-based automation. A few techniques/concepts that have proven capabilities for defect and material characterisation include; ultrasonic phased array (ALOK), time of flight diffraction (TOFD) and synthetic aperture focusing technique (SAFT). Electromagnetic acoustic transducers (EMAT), being of the non-contact type offer the potential advantage of performing inspection of high temperature components without the need for any physical coupling. Similarly, laser generated ultrasonic sound generation and interferometric detection techniques show a great promise in this regard for characterisation of materials at high temperatures or in hazardous environments. This technique has been used to detect laminar defects in red-hot steel billets. Space limitations preclude full-fledged discussion of these advanced techniques. However, the reader may refer to the literature available on these topics (Silk 1984; Muller et al 1986; Bohn et al 1987).

Ultrasonic phased arrays hold out considerable promise. By using a number of elements excited with different time delays, it is possible to both steer and focus the beam in transmission and to image on reception of the beam. The ability to electronically control the beam characteristics of the phased array probe has an attraction in automated systems where a large number of different probe angles may be utilised for reliable inspection (Cochran et al 1991). 
ALOK (Amplituden und Laufzeit Orts Kurven) meaning "amplitude and time of flight locus curves" is a recent development with its origin in Germany. This method incorporates all the features required for automated inspection of pressurised components in any industry viz. high sensitivity and resolution, reliability and reproducibility, quick information on the condition of the component and ability to analyse a crack without re-examination. These inspection systems have the capability to detect cracks even in complex geometries. In contrast to conventional assessment of amplitude information, the ALOK method uses the time-of-flight of the echo signals to get complete information about the cracks like its position, size, shape and orientation. The time-of-flight locus curves are obtained from the time-of-flight (e.g. echo from a reflector) vs. probe position during its transit. To get the time-of-flight (and the corresponding amplitude) information, only the peak amplitudes from an A-scan and their times-of-flight (selected out of the $\mathrm{rf}$ signal) are recorded. This results in significant reduction in data without any loss of information. The data are also displayed in the form of B- and C-scans. Flow reconstruction is made by geometric planar triangulation or by iterative methods.

SAFT is another promising technique in ultrasonic NDE. The basic idea of SAFT is to measure the complete sound field scattered by a crack on an orbit around the crack. During reconstruction, this sound field is calculated back into that region where the scattering occurred making use of well-known wave propagation formulae. The result is the three-dimensional amplitude distribution of the sound field inside the scanned orbit. In an ideal case, sound field will be non-zero only on the surface of the scatterer, thus obtaining an image of the crack by describing its surface. Because a $360^{\circ}$ scanning around a defect may be possible only in a few cases like rods or shafts, one is forced to reduce the scanned aperture to only the part corresponding to the accessible surface. Therefore, only that part of the crack which could be interrogated by the ultrasonic beam would be imaged. To maximize the interrogated area of the crack, probes with large beam opening angles have to be used i.e. small probes or the defocused part of the far field probes. In addition, it is possible to synthesize scanning around the defect using different beam angles and different inspection techniques like pitch-catch or tandem.

Another innovation in the recent past is the time-of-flight diffraction (TOFD) technique. TOFD is widely used for accurate location and sizing of cracks. Interaction of an acoustic wave with a crack results in the generation of diffracted waves. It is important to note that the diffracted energy can produce a significantly large pulse. While this pulse will be smaller than the largest that can be obtained with reflection techniques, it will usually be comparable with pulse echoes obtained in practice. As a result of diffraction, a cylindrical wave front effectively originates at the crack tip. By suitable measurements of this diffracted wave, it is possible to locate the origin of the cylindrical wave, or in other words, to locate the tip of the crack. This leads to the concept of the use of diffracted ultrasound to size cracks. In order to achieve this, the most obvious measurements to make on the diffracted pulses are their arrival times. This, in turn, couples 'diffraction' and 'time of flight' together. The technique was originally pioneered on surface-breaking cracks. But, with improvements in data processing techniques, it has been possible to evaluate subsurface and internal defects. The technique produces a significant improvement in accuracy of defect sizing as compared to conventional pulse echo data (Temple 1987).

The technique that has established itself as a powerful tool for defect and material characterisation during PSI and ISI is acoustic microscopy. Acoustic microscopy 
produces very high resolution and high magnification images of internal features in a component through the use of short wavelength (very high and ultrahigh frequencies) ultrasound. There are three types of acoustic microscopy systems. They are scanning acoustic microscopy (SAM), scanning laser acoustic microscopy (SLAM) and C-SAM. In SAM, a point source of ultrasound is produced in a fluid such as water by a highly focused transducer. The transducer is pulsed and alternately acts as a transmitter and receiver. The transducer scans in a rectilinear raster pattern to obtain the image. In SLAM, a focused laser beam is employed as an ultrasonic wave detector by virtue of the fact that displacement at an interrogated surface modulates light reflected from the material. The displacement is localised within acoustic dimensions. The image of the sample is produced by using plane waves of ultrasound and scanning by laser over the field of view at the rate of 30 images per second which is about 300 times faster than SAM. SLAM is generally used in transmission mode whereas SAM is used in reflection mode. C-SAM is somewhat analogues to the C-scan ultrasonic technique. The acoustic microscopy techniques have been used for detection and characterisation of cracks in a variety of materials such as ceramics, metals, polymers and composites and they have the capability to be utilised from initial characterisation of the base materials to the final quality check of the precision fabricated assemblies. They have been found useful in crack detection in thin, flat or smoothly curved surfaces. With the use of phased array and a solid coupling system, acoustic microscopy could become an effective method for inspecting components/structures both during pre-service and in-service. This method has been used to detect and characterise surface and sub-surface cracks down to 100 microns in ceramics (Baldev Raj et al 1994b).

Fibre-reinforced composite materials are being increasingly used in defence, space and commercial applications due to their low weight, high strength and stiffness properties. This neccesitates the development and standardisation of NDE techniques for meeting fitness-for-purpose requirements. UT enjoys the status of being a reliable method for evaluation of composite structures in spite of the difficulties posed by composite structures, for example high attenuating behaviour, heterogeneous nature and anisotropic properties. Different kinds of defects that can occur in fibre-reinforced plates during fabrication and in-service are contaminants, voids, unpolymerised resin, resin-rich and resin-starved areas, ply gaps, foreign inclusions, delaminations, crazing, surface scratches etc. Detection and characterisation of some of these defects has been carried out by us using an automatic ultrasonic scanning system. Two different experimental methods (ultrasonic immersion and dry coupling) have been used. For effective detection and characterisation of defects, procedures have been developed using advanced signal processing and analytical approaches such as auto-power spectrum, total spectral energy content and demodulated auto-correlation pattern etc. (Kalyanasundaram et al 1991b).

In the area of microstructural characterisation, we have successfully adopted ultrasonic velocity and attenuation measurements in the following applications; (i) characterisation of precipitation behaviour and estimation of volume fracture of $r$ ' in Nimonic alloy PE 16 (ii) assessment of microstructural degradation (dissolution of tempered martensite structure to ferrite and carbides) in 9Cr-1 Mo steel, (iii) chracterisation of precipitation hardening behaviour in 17-4 PH steel (iv) chracterisation of various microstructures in A533B pressure vessel steel, (v) estimation of porosity in aluminium alloy weldments, (vi) determination of texture coefficients in cold worked AISI type 304 stainless steel, and (vii) assessment of creep damage in low alloy ferritic 
steels (Jayakumar et al 1992a). Many of these results would be useful in developing procedures for micro-structural degradation and damage assessment applications utilising ultrasonic techniques (Bhattacharya et al 1993; Jayakumar et al 1993, 1994).

Ultrasonic velocity measurements are useful for determining several important material parameters like moduli, Poisson's ratio, residual stresses, texture, porosity and characterisation of secondary phases in microstructure etc. Some of these parameters influence the velocity only by an order of $0 \cdot 1 \%$. In order to study these variations, high resolution techniques for ultrasonic velocity measurements are necessary. We have devised a methodology for precise ultrasonic velocity measurements using crosscorrelation technique. The accuracy in the velocity measurements is enhanced by adopting cubic spline fitting of the cross-correlation function. The resolution in time delay measurements required for computing the velocity was of the order of $0.5 \mathrm{~ns}$. This methodology has been applied for finding the influence of microstructure on ultrasonic velocity in $9 \mathrm{Cr}-1$ Mo ferritic steel and 17--4 PH stainless steel (Rao et al 1993b). In the next sub-section, the possibility for use of ultrasonic velocity measure-ments in aiding quality control during fabrication and damage assessment during service are discussed.

2.5a Ultrasonic velocity measurements for microstructural evaluation in $9 \mathrm{Cr}-1 \mathrm{Mo}$ steel-A case study: $9 \mathrm{Cr}-1 \mathrm{Mo}$ steel is a candidate material for boiler/super heater steam circuitry of power plants. Ultrasonic velocity measurements were carried out on varieus heat-treated $9 \mathrm{Cr}-1 \mathrm{Mo}$ ferritic steel specimens with a view to study the influence of microstructure on ultrasonic velocity. Heat treatment consists of aging treatment at 823,923 and $1023 \mathrm{~K}$ for durations of $2,10,50,200,500$ and $1000 \mathrm{~h}$. Ultrasonic velocity measurements were carried out on these specimens using a $15 \mathrm{MHz}$ longitudinal transducer. The microstructure after standard treatment (normalising at $1323 \mathrm{~K}$ for $30 \mathrm{~min}$ followed by tempering at $1023 \mathrm{~K}$ for $1 \mathrm{~h}$ ) is martensite with $\mathrm{M}_{2} \mathrm{X}$ carbides at lath boundaries and small amounts of ferrite due to partial dissolution of martensite (reference specimen). The reference specimen has the lowest velocity compared to all the aged specimens. At all the temperatures, it is observed that as the aging time increases, velocity first increases and then decreases or remains almost constant after attaining a peak depending on the temperature. The increase in velocity is lower at $1023 \mathrm{~K}$ as compared to that at 823 and $923 \mathrm{~K}$. This is attributed to the formation of smaller volume fraction of $\mathrm{M}_{2} \mathrm{X}$ at $1023 \mathrm{~K}$ due to simultaneous formation of ferrite and $\mathrm{M}_{23} \mathrm{C}_{6}$ by dissolution of some of the martensite. It can also be observed that the maximum in velocity has occurred at lower durations of aging with increase in aging temperatures due to faster precipitation of carbides at higher temperatures. The time periods for maximum in velocity at 823,923 and $1023 \mathrm{~K}$ are 200,100 and $10 \mathrm{~h}$ respectively. At $1023 \mathrm{~K}$ beyond $10 \mathrm{~h}$ of aging, the velocity is found to decrease steadily whereas at 823 and $923 \mathrm{~K}$ the velocity remains almost constant or decreases slightly after attaining the peak. The steady decrease in velocity at $1023 \mathrm{~K}$ after $10 \mathrm{~h}$ of aging is attributed to the continuous dissolution of martensite forming ferrite and $\mathbf{M}_{23} \mathrm{C}_{6}$. Since very little or no ferrite formation takes place even upto $1000 \mathrm{~h}$ at 823 and $923 \mathrm{~K}$, the velocity remains constant after attaining the peak.

These measurements clearly indicate that formation of $\mathrm{M}_{2} \mathrm{X}$ precipitates and ferrite influence the ultrasonic velocity. Any increase in velocity with time at a given location on a component indicates formation of precipitates of $\mathrm{M}_{2} \mathrm{X}$. Similarly, a decrease in velocity with time clearly indicates formation of ferrite which reduces the strength properties. Similarly, for a given material, the influence of an unwanted phase in other 
materials on the velocity can be established and in-service degradation can be assessed periodically by performing velocity measurements.

\subsection{Acoustic methods}

Acoustic methods (AM), also known as sonic testing; vibration testing and mechanical impedance testing, depend on exciting vibrations in a specimen by local impact and then measuring some properties of the vibrations such as resonance frequency, decay time etc. A simple example of an acoustic method is the inspection of a railway wheel by tapping it with a hammer and detecting the vibrations with a transducer. There are several other important applications of acoustic methods, the most important being testing of cast iron specimens where it has been shown that the nature and size of carbon content can be related directly to the reasonance frequency of the casting. This method is extensively used for quality control of malleable iron castings. Bonded joints, defects in composites and plastic components have been located and assessed using this technique. Testing of adhesive bonding in laminates and honeycomb structures for aerospace applications is nowadays carried out by these methods. Using much lower frequencies of the order of a few kilohertz, masonry structures have been tested by these methods. The structure is excited by a blow with a steel-tipped hammer and the frequency of the propagated signal is analysed through a transient recorder in conjunction with a computer. When the method was applied to masonry bridge structures, the signal was found to be sensitive to significant defects such as large voids and cracks (Halmshaw 1989).

Vibration monitoring of operating plant and machinery to give early warning of impeding failure or potential fault conditions forms a popular NDE method. Even the most simple machinery has a number of sources of vibration and these vibrations are transmitted through the machine structure. The vibration spectrum depends on the machine speed, loading, lubrication etc. The vibration is characterised by amplitude, frequency and phase and is usually measured by a small electromechanical transducer that senses displacement, velocity, and acceleration. Periodic measurements carried out on a machine provide information on any significant changes that are indicative of deterioration in the machinery. These measurements may be continuous, on-line or periodic.

\subsection{Eddy current testing}

Eddy current testing (ECT) methodology uses the principles of electromagnetic induction to inspect electrically conducting components for detection, characterisation and classification of abnormalities. In ECT, an alternating current (frequency range $\mathrm{kHz}-\mathrm{MHz}$ ) is made to flow in a coil (also called probe) which, in turn, produces an alternating magnetic field around it. This coil when brought close to the electrially conducting surface of the material to be inspected, induces an eddy current flow in it due to electromagnetic induction. These eddy currents are generally parallel to the direction of coil winding. The presence of any defect or discontinuity in the material disturbs the eddy current flow. These eddy currents, in turn, generate an alternating magnetic field (in the opposite direction) which may be detected either as a voltage across a second coil or by the perturbation of the impedance of the original coil (Libby 
1971). The impedance change in the probe coil is mainly affected by electrical conductivity, magnetic permeability and geometry of the material test frequency, spacing between the coil and the material (also called lift-off or fill factor), and also by the presence of any defect or discontinuity in the material. The impedance change can be measured and can be correlated with changes in the above parameters. When an eddy current probe is scanned over a component consisting of a defect, the amplitude of the eddy current signal (impedance change trajectories) provides information about the severity of the defect, and the phase angle provides information about its depth. Natural cracks or sets of artificial defects made by electric-discharge machining(EDM) or specially produced fatigue cracks are used to calibrate the ECT instruments and to characterise cracks/defects in a reliable manner.

A change in microstructure is generally associated with a change in either electrical conductivity or magnetic permeability. Hence, ECT can be used to assess microstructural degradation of components. While dislocation structures and residual stresses created in the materials affect the electrical conductivity, the formation of magnetic phases affect the magnetic permeability. Studies were carried out by us on the solution annealed AISI 304 stainless steel plates subjected to different degrees of cold work. A good correlation was observed between degree of cold work and the ECT output. Formation of magnetic phases beyond $25 \%$ cold work was also observed and confirmed qualitatively by ferritoscope and microscopy (Kasiviswanathan et al 1986). These studies clearly indicate the possible use of ECT for detection and quantification of microstructural degradation. Other important applications of ECT include metal sorting, thickness measurement, corrosion monitoring, fatigue crack detection, liquid sodium level monitoring, conductivity measurements etc.

During the last two decades, significant progress has been made in the theoretical and practical aspects of ECT (Shyamsunder \& Rao 1992). Axi-symmetric finite difference and finite element models (FEM) have enabled understanding the physics of electromagnetic field/defect interactions. At our laboratory, the work has shown significant promise. A 2D FEM code capable of operating on a personal computer has been developed. This model has been used to predict the impedance changes, the magnetic flux line and eddy current density contours to typify the interactions in ECT. The model was used to optimise probe design for garter spring location in the coolant channels of Pressurised Heavy Water Reactors, the details of which would be given in the case study described at the end of this section. Signal trajectories were predicted for various coil designs (of same cross-sectional area) and optimum design parameters viz. width of coil, depth of coil and spacing between two differential coils of the probe were arrived at, considering the maximum amplitude signal with differential nature. Very good agreement between the predicted and experimental trajectories was observed for ECT probes with varying design parameters due to the presence of a garter spring (Rao et al 1990).

Stress corrosion cracking is the major failure mode observed in the case of heat exchanger tubes, since they are subjected to continuous flow of high temperature fluids, steam, and other aggressive environments. The deterioration of the tube materialleads to the possibility of leaks. ECT is the most popular technique for periodic monitoring of these tubes because of its ease of operation, versatility and reliability. Conventional single frequency ECT is inadequate when interferences arise from such sources as support plates and other interferences/structures. Many a times, it is under the support plates that corrosion damage often takes place. Multifrequency techniques which 
eliminate signals from unwanted parameters like support plate, probe wobble etc. are widely used. This technique involves simultaneous excitation of more than one frequency in ECT probe and processing of the corresponding analog signals to eliminate signals due to unwanted parameters. We have standardised procedures for condition monitoring of steam generators and condensers using two frequency ECT and successfully carried out inspection of such components in power and petrochemical industries. Procedures have also been developed by us to eliminate three parameters (support plates, probe wobble and sodium deposits) that would be present during ECT of heat exchangers of fast breeder reactors (Rao et al 1989).

ECT of ferromagnetic heat exchanger tubes is difficult due to their high and continuously varying magnetic permeability. These variations produce high amplitude ECT signals that mask the signals from defects. The use of magnetic saturation can overcome these difficulties to a large extent. Ferromagnetic tubes can be satisfactorily inspected by ECT if they are magnetically saturated. Magnetic saturation essentially indicates a condition where all magnetic dipoles are aligned in the same direction parallel to each other and the material starts behaving non-ferromagnetically. Magnetic saturation is easily achieved during tube manufacture using an external DC saturation coil and eddy current testing is carried out using an encircling eddy current probe. However, the same cannot be implemented during in-service inspection (ISI) of heat exchangers or steam generators due to limited space from the boreside of the tube. In-service inspection of ferromagnetic tubes by eddy current testing (ECT) is a major challenge. In this area, we have successfully designed high strength $\mathrm{SmCo}_{5}$ permanent magnet-based eddy current probe and results were evaluated using a calibration tube with artificial defects (Shyamsunder et al 1993).

For pre-service and in-service inspection of ferromagnetic tubes, a new technique that is showing great promise and potential is remote field eddy current testing (RFECT). The primary advantage of this technique is the ability to inspect tubular products with equal sensitivity to both internal and external metal loss or other anomalies, linear relationship between wall thickness and the measured phase lag and absence of lift-off problems. The technique features the ability to inspect both ferro and non-ferromagnetic materials with equal sensitivity to internal or external anomalies (Kilmore \& Ramachandran 1989). Pioneering work has been carried out by us with respect to the development of an RFECT instrument and the computer simulation of the technique. Wall loss down to 15\% was detected using an indigenously developed RFECT instrument. The presence of transition and remote field zone and the affect of tube diameter and wall thickness on them have been studied using a 2D-FEM code (Rao et al 1993a). Efforts are underway to optimise the frequency and other parameters to obtain better detection sensitivity.

At our laboratory, procedures employing ECT for integrity evaluation of small diameter thin wall fuel cladding tubes of fast reactors (Fast Breeder Test Reactor, $5.1 \mathrm{~mm}$ outer dia and $0.38 \mathrm{~mm}$ thick; Prototype Fast Breeder Reactor, $8.2 \mathrm{~mm}$ outer dia and $0.5 \mathrm{~mm}$ thick) have also been standardised. Seven percent wall thickness deep longitudinal and transverse notches and natural defects produced during manu- facturing stage have been successfully characterised (Barat et al 1982). Complementary capabilities of ECT and ultrasonic testing techniques have been established. These procedures are applicable for carrying out NDE during manufacturing stages, prior to and after irradiation stages. The special probes and gadgetries required for carrying out inspection of irradiated fuel cladding tubes, because of radioactivity and other associated problems have been developed in-house. 
One recent technique that has shown tremendous potential in detecting defects in expansion transition zones and rolled joints of heat exchangers with equal sensitivity to both longitudinal and transverse defects in Phased Array ECT (PAECT). This system uses a substantially different bridge circuit and probes that produce a constant magnitude rotating magnetic field which is insensitive to expansion transition zone, tube sheet or support plate. We have designed and developed a tandem PAECT probe that minimises the insensitive zones, in turn, leading to enhanced sensitivity for inspection of tubes (Shyamsunder et al 1994).

ECT has benefited with the availability of relatively low cost Personal Computers (PCs) and the accompanying revolution in digital technology (Rao et al 1992). A recent outcome of these advances in the area of ECT is eddy current imaging (ECI). We have developed computer-based ECI system to scan the object surface and create impedance images in the form of gray levels or pseudo colours. This consists of a PC-controlled $X-Y$ scanner which scans the component point-by-point in a raster fashion with an ECT probe, acquires data using a 12-bit analogue to digital converter card, and finally processes and displays data in the form of images. Using ECI, it is possible to obtain images of defects in two dimensions enhancing the defect detection capability. Fatigue cracks, corrosion pits, EDM notches and other types of defects have been imaged and characterised (Rao et al 1993c). In the case of fatigue cracks, ECI is found to be capable of revealing the orientation of the crack which is an important feature for fatigue crack growth and fracture mechanics studies. ECI has also been used to detect the weld centre line in stainless steel welds with an accuracy of $0.1 \mathrm{~mm}$. This could enable scanning of the welds during angle beam UT and obtaining accurate information on defect location. Other developmental works carried out include: optimisation of probe design for ECI and implementation of filtering and image processing methodologies to improve the quality of images. The above discussions clearly indicate the potential of $\mathrm{ECI}$ in detecting and characterising defects in metallic materials effectively.

NDE plays a major role in ensuring safe and reliable operation of Indian nuclear reactors. One of the important condition monitoring technique used in these reactors is ECT. In the following section, such application of ECT i.e. structural integrity evaluation of pressure tube (PT)/Calandria tube (CT) assemblies of Pressurised Heavy Water Reactors (PHWRs) is discussed.

2.7a ECT for structural integrity of PT/CT assemblies - a case study: Pressurised Heavy Water Reactors are the backbone of India's nuclear power programme. These reactors use naturai $\mathrm{UO}_{2}$ as fuel and heavy water as moderator (that slows down the neutrons for their effective participation in the heat generating fission reaction). These reactors are located at Kota, Rajasthan (RAPS) Kalpakkam, Tamilnadu (MAPS), Narora, Uttar Pradesh (NAPS) and Kakrapara, Gujarat (KAPP). A typical $235 \mathrm{MW}$ PHWR consists of 306 channels. Each of these channels consists of a pressure tube $(9220 \mathrm{~mm}$ long, $82.6 \mathrm{~mm}$ dia and $4 \mathrm{~mm}$ thick) made of Zircaloy-2 which is positioned horizontally between two tube sheets. Each PT contains 12 fuel bundles and heavy water coolant passes through it. The outlet from all 306 PTs forms the primary heat transport system. Each PT is surrounded by a Calandria tube $(107.8 \mathrm{~mm}$ diameter and $1 \mathrm{~mm}$ thick) again made of Zircaloy-2 leaving a nominal gap of $8.5 \mathrm{~mm}$. Outer regions of the CT form the moderator system. Garter springs (two in earlier reactors and 4 in more recent reactors) are positioned in each of the annular channels so that gaps between the PTs ad CTs are maintained (i.e. they do not touch each other during 
reactor operation) to prevent heat transfer from primary heat transport system to moderator system. The garter springs are made of an alloy of zirconium, niobium and copper. The material of construction of PTs and CTs is changed to zirconium- $2.5 \%$ niobium alloy from Kakrapara Atomic Power Project (KAPP) onwards because of its better creep and corrosion properties.

Subsequent to the failure of a PT in the Pickering-2 reactor, similar to PHWR, in Canada in 1983, it was realised that the garter springs could get displaced during hot conditioning and/or during the operating of the reactor (Field et al 1984). This displacement increases the unsupported length of the PTs. This increase, coupled with the in-reactor creep of the PTs may make the outer surface of the PTs (at a max. temp. of $548 \mathrm{~K}$ ) touch the cold inner surface of the C Ts (at a temperature of $333 \mathrm{~K}$ ) leading to the formation of a cold spot and, further, to the generation of massive hydrides through intense hydrogen diffusion to the cold spot region. This, in turn, results in formation of blisters and cracks leading to ultimate failure of the PT. In view of this, the structural integrity of PTs needs to be considered not only with respect to their own properties, but together with the CTs and the garter springs as well. This can be accomplished by performing NDE at various stages viz. during pre-hot conditioning, post-hot conditioning and in-service to monitor the following:

(a) location of garter springs between PT and CT;

(b) profiling of gap between PT and CT;

(c) defect detection in PT.

ECT has been proven to be one of the best technique to fulfill the above mentioned requirements. Development of procedures, design of required ECT probes and training of personnel for carrying out the above mentioned assignments have been undertaken by the authors' laboratory. FEM model has been developed and used to optimise probe design for garter spring locations. Such probes have been successfully used for carrying out PT inspections at various PHWRs. The accuracy of garter spring locations has been $\pm 5 \mathrm{~mm}$ and that of gap profile $\pm 0.5 \mathrm{~mm}$. Significant work has also been done at the authors' laboratory for the development of a PC-based data acquisition system for acquiring data from an ECT equipment and a database software package for documentation, evaluation and analysis of garter spring data from different reactors during various inspection campaigns ( $R$ ao et al 1991). The defect detection in the PTs is mainly concerned with the detection of localised hydride blisters, if any. However, other types of defects may also be present. In a full-scale mock-up assembly consisting of various artificial notches, $5 \%$ wall thickness deep longitudinal notch and $8 \%$ wall thickness deep transverse notch were detected unambiguously.

\subsection{Potential drop techniques}

Potential drop technique is widely used for crack depth measurements in metallic materials. A crack detected by other NDT techniques can be reliably assessed for its length and orientation by this technique. Also this technique is used to monitor the growth of a crack during the service life of a component. The instruments required for this technique are simple. and portable. Basically, there are two types of techniques, namely Direct Current Potential Drop (DCPD) technique and Alternating Current Potential Drop (ACPD) technique. While the former is useful for detecting and assessing surface and subsurface defects, the latter is useful for detecting and assessing 
only surface defects since current is confined to the surface layers only due to classical skin effect phenomenon (Baldev Raj et al 1994b).

In these techniques, current is sent into the component perpendicular to the crack through two current electrodes, and the voltage drop across the crack is measured using two voltage electrodes for the current electrodes themselves and also called probe) and evaluated for parameters of the crack such as depth and inclination to the surface. When the two electrodes of the probe separated by a distance of $D$ units, straddle a crack of depth $h$, the path length between the electrodes becomes $D+h$, producing a potential difference of $V 2$ as against $V 1$ for crack-free regions. The potential differences $V 1$ and $V 2$ are measured and the crack depth is computed. The instrument, therefore, consists essentially of a power supply unit to set up the field and a sensitive voltmeter and a suitable probe with two current points spaced by a known distance. The DCPD technique is not affected by the magnetic permeability, but only affected by the electrical resistivity and the geometry of the specimen. In order to evaluate the crack parameters from the measured voltages, calibration charts are needed. We have used this technique to size the fatigue cracks detected by magnetic particle inspection technique in a turbine rotor.

Numerical modelling offers the possibility of obtaining calibration charts for specimens and cracks with complicated geometries and with variations in material properties. Because of need for good electrical contact. the ACPD technique requires extensive cleaning of the component surface. This makes it difficult to deploy in the field. Also the ACPD technique is really suited only for the sizing of cracks already found by other techniques. These drawbacks can be overcome by adopting new technique called alternating current field measurement (ACFM). ACFM involves the measurement of magnetic field disturbances rather than electrical fields. The electrical field is introduced by induction (and therefore requires no electrical contact) and the probe is designed to introduce a uniform input field approximately perpendicular to the expected orientation of the crack. With two orthogonal field sensors, it is possible to both detect and size surface breaking defects without calibration. This technique has been successfully used for reliable and cost-effective inspection of wide range of metallic components including offshore platforms/structures, pressure vessels. pipe supports, threads, sub-sea structures etc. (Topp 1994).

\subsection{Acoustic emission technique}

Acoustic Emission Technique (AET) has established its rightful place among the available NDE techniques. Acoustic emissions (AE) are the spontaneously generated elastic waves created by discrete movements within the volume of a material being stressed. AE can be detected from the movements as small as those created by phase transformations within a crystalline structure or from movements as large as the propagation of a fatigue crack under low cycle fatigue conditions. Thus, an AE source is the site of a dynamic change in the material which responds to stimuli by releasing part of the energy in the form of elastic stress waves (Mclntire \& Miller 1987). This dynamic nature of AET makes it a highly potential technique for monitoring the structural integrity of components/structures in various industries with respect to identifying growing cracks in them. AET enables detection and location of defects even in complex geometries. The detection of AE is usually accomplished with a piezoelectric crystal sensor coupled to the part under test. The sensor output is amplified through a high 
gain-low noise preamplifier, filtered in order to remove any extraneous low frequency hardware noises, conditioned and displayed. Conventional displays of $\mathrm{AE}$ data depict rate of $\mathrm{AE}$, total cumulative counts and amplitude of $\mathrm{AE}$, r.m.s. voltage versus other environmental parameters such as load, temperature, time etc. Various AE signal parameters helpful in evaluating cracks include ringdown counts, events, peak amplitude and their distributions, r.m.s. value, rise time and event duration. Signal analysis, pattern recognition and neural network approaches offer promising possibilities for enhancing the usefulness of this technique.

AET is particularly useful for monitoring structural integrity as it can detect growing cracks down to size of 25 microns, even in the presence of noisy environments. Also, the cracks originating from the inner surface are as easily detectable and distinguishable as those from the outer surface. AET assesses the behaviour of defects under test conditions, an information of major significance for performance evaluation. Further, AET is very useful in predicting fatigue failures in advance (Moore \& Tsang 1977). AET has been successfully applied to the detection and monitoring of corrosion fatigue, hydrogen embrittlement and stress corrosion cracking. The inherent advantages of AET are that it is non-localised, it is not necessary to examine specific regions of a structure - a large volume can be tested at one time etc. Many components in high performance aircraft structures are fabricated from structural alloys which, while having high strength levels, have relatively poor crack arresting capability. Small cracks, which have a greater potential to remain undetected, can approach critical size with very little extension. For these types of structures, only AET offers reliable capability to detect any increment of crack growth during structural loading. AET is best suited for on-line monitoring of welds, as it can detect and locate weld defects as they occur. This possibility enables control of quality and any repairs required can be carried out expeditiously and economically. Event rate and r.m.s. voltage of AE signals could be used to detect, locate and differentiate weld cracking, inclusions and process equipment malfunctions like short circuit, current variations and arc drifting etc. (Holroyd 1986).

In our laboratory, we have emphasized the use of AET for both structural integrity monitoring and materials research applications (fracture, deformation, phase transformations, oxidation etc.) (Khanna et al 1987; Baldev Raj et al 1989, 1990). AET has been used to assess the integrity of pressurised components in operating plants by way of detecting leaks. Pressurized pipes, such as gap pipe lines and heat transport piping in power stations, are generally designed to satisfy the leak-before-break concept (i.e. a crack in a tube grows to cause a small leak long before reaching the critical crack size for catastrophic pipe rupture). However, this concept requires that a leak is detected at an early stage. Thus, AE monitoring is a potential technique for continuous surveillance for detection of cracks (Jayakumar et al 1992b).

AET has been applied at the authors' laboratory for understanding deformation and fracture process in austenitic alloys (AISI type 316 stainless steel and Nimonic alloy PE-16), oxidation behaviour in ferritic steels, glass-crystalline transition temperature determination and structural relaxation studies in metallic glasses and martensite transformation in unstable austenite (AISI type 304 stainless steel). In the case of Nimonic PE-16 alloy, various AE parameters have been used to correlate the $\mathrm{AE}$ behaviour with particle shearing and Orwan looping processes taking place in the presence of gamma prime and decohesion and fracture of MC occurring during tensile deformation (Jayakumar et al 1991). AET has been used by us to study martensite formation in cold worked AISI type 316 stainless steel during cooling after aging and to 
determine the temperature range for its formation during cooling (Mukhopadhyay et al 1994).

As the AE signals generated in austenitic stainless steel are weak, an innovative technique has been developed by us to amplify the AE signals (Baldev Raj et al 1990). The technique is based on the understanding that external injection of ultrasonic waves simultaneously is expected to interact with subcritical $\mathrm{AE}$ sources and give rise to enhanced AE signals which otherwise would not have been released at those stress levels. Amplification factors of 2 to 20 could be obtained for peak-to-peak voltage of 0.2 to $0.7 \mathrm{~V}$ of the injected signals (Baldev Raj 1990). AET has also been applied for finding possible growth of a repaired crack during service of a pipeline carrying steam at high pressure and temperature. Comparison of $\mathrm{AE}$ data near the crack region and at a region away from it indicated events with higher mean peak amplitude near the crack region indicating growth of crack. Subsequent radiographic examination indicated missing of root-pass weld which might have acted as the source for stress concentration/crack initiation. In the following section, a case study highlighting the successful application of AET for detection and location of leak paths in the end shield and pressure tubes of PHWRs is discussed.

2.9a AET for leak detection in PHWR components: AET has been successfully applied for detection and location of leak paths present on an inaccessible side of an end shield of unit 1 of Rajasthan Atomic Power Station (RAPS) (Kalyanasundaram et al 1989). This methodology was based on the fact that air and water-leak AE signals have different characteristic features. Baseline data was generated from a sound end shield of a PHWR for characterising the background noise. A mock up end shield system with saw-cut leak paths was used to verify the validity of the methodology. AET was carried out to detect light-water leakage from one of the end shields. Time-domain analysis of AE signals obtained by air pressurisation of the end shield to $0.124 \mathrm{MPa}$ was used for detection and location of leak paths. However, time-domain analysis could not be applied for detection of subsequent leaks, found after repair and operation of the system, as there was limit on maximum air pressurisation of the end shield to $0.035 \mathrm{MPa}$. Since, the timedomain analysis did not provide any meaningful results, frequency spectral analysis approach was used. Autopower spectra showed presence of characteristic frequency associated with the air leaks. It was also observed that the chracteristic frequency of the signal was different for the two leak paths and was attributed to the size, shape and morphology of the leak paths. In another instance, for findings a leaking pressure tube of MAPS, another PHWR type of reactor. advanced frequency analysis approaches have been adopted (Kalyanasundaram et al 1992). In this case, simple frequency spectrum could not be used for detection of the leaking pressure tube. Only by using the spectral energy ratio at two different frequency bands and its change with pressure, it was possible to identify the leaking pressure tube. The above studies indicate the advantage of frequencydomain analysis over time-domain analysis for detection and location of leaks occurring relatively at low pressures and under noisy environments.

\subsection{Infrared thermography}

Infrared thermography (IRT) refers to the mapping of the temperature profiles on the surface of an object. This technique utilises the infrared spectral band of the electromagnetic 
radiation. With the aid of a suitable detector, infrared radiation can be converted into an image and visualized for interpretations. The method uses a special television camera with an IR sensitive detector and a lens which transmits IR radiation. Such cameras can operate at conventional video rates. The temperature variations in the object under investigation are displayed as shades of gray or can be converted into a pseudo-colour image. Temperature variations as small as 0.2 degrees can be detected. At ambient temperatures and above, all objects emit electromagnetic radiations predominantly in the infrared region which is invisible to the eye. Variations in the temperature of the surface of the object can be converted into a thermal image and visualised. This helps detection of deviations from normal temperature distribution, from a distance. It is this advantage that the technique exploits. The basic idea behind thermographic NDE is that if a pulse of heat is applied to one side of a specimen, the spatial distribution of the heat flux on the opposite surface will depend on the homogeneity of the specimen (i.e. the presence of internal defects), the diffusivity (which is related to thermal conductivity and volume capacity) and time. The difference between thermographic methods and other methods using electromagnetic radiations is that in the IRT method the heat is propagated by a diffusion process and not instantaneously. The difference in temperature on the surface facing the detector can be measured and related to the size of the internal defect. Infrared thermography can be classified basically into two categories viz. passive and active. In passive technique, the natural heat distribution is measured over the surface of a hot structure. This is generally used for temperature monitoring of structures for assessing their integrity. In an active technique, heating or cooling is induced or applied to the part or complete surface and the redistribution of heat or temperature across of test surface is measured. This is generally used in NDE (Baldev Raj et al 1990a).

IRT has several important features which make it attractive for inspection of materials, components and plants. The method is non-contact, dry, safe, fast and displays results of inspection in a convenient visual format. IRT has established a unique position for testing and evaluation of circuit boards, transmission lines, furnaces, air-conditioned enclosures, gas and fluid transfer lines etc. This technique is ideally suited for wear determination of refractories in blast furnaces, hot blast stoves and steel stoves and in the inspection of rotary kiln lining. It has been proved to be a very important tool for predictive maintenance in electrical systems. It can locate any impending failures or locate points which are likely to cause trouble. The technique, being noncontact, is very promising for remote applications.

In the field of materials evaluation, IRT has been applied for monitoring fatigue damage and for mapping of stress fields during cyclic mechanical testing. The technique has also found applications in the control of hot rolling and welding process, detection of surface cracks and surface defects in induction-heated hot-rolled plates (Kubiak 1968). Recent applications of thermography include on-line detection of hot spots, fatigue damage and weld defects in components. Detection of initiation and growth of cracks is also possible using this technique (Cielo et al 1987).

Thermography is used extensively to monitor the structural integrity of electrical plants and substations (Venkatraman et al 1992). In this direction, various condition monitoring campaigns have been successfully performed by the authors' laboratory, some of them include; $230 \mathrm{kV}$ main transformer of PHWRs, $33 \mathrm{kV}$ switchyard at Indira Gandhi Centre for Atomic Research (IGCAR) and concrete wall of turbine building of Fast Breeder Test Reactor (FBTR). Similarly, IRT has proved to be indispensable for 
predictive maintenance in petrochemical industry. In a campaign at a petrochemical industry, hot oil heaters, charge heaters and stack duct-to-air preheaters were inspected by us. Hot spots were observed in certain zones on the hot oil heaters. They were attributed to thinning down of the refractory lining inside the oil heaters and recommended for maintenance during subsequent shutdown. The above-mentioned campaigns have clearly established the capability of IRT technique for condition monitoring.

Apart from this, thermography is being used as a valuable tool for the investigationof weld pools. At our laboratory, studies are being carried out on the adaptability of thermography for on-line monitoring of welds (Venkatraman et al 1993a). Thermographic methods are widely used in aerospace and transport industries for the testing of non-metallic materials such as composites and laminates where conventional NDE techniques like RT and UT produce results which are difficult to interpret. IRT has proven to be a valuable tool for detection of impact damage, debonds etc. in composites (McLaughlin et al 1980).

\subsection{Laser holography}

Holography is becoming more and more popular in NDE as its capabilities are understood better. When light is incident on an object, the envelop of the scattered light (called object wave front) contains the visual information of the object. Holography is a technique for recording and reconstructing this object wavefront. Holographic interferometry (HI) technique essentially involves the interference of the object and reference beams (laser) emanating from the component under investigation and recording of the interference pattern on a high resolution photographic plate (hologram). The information in the hologram is extracted by reconstruction of the image by passing a wave similar to the reference beam. The $\mathrm{HI}$ technique, being non-contact, is finding place as a complementary or sometimes unique NDE technique in many specialised applications. It is being routinely used in the aircraft industry for inspection of aircraft tyres, microwave antenna etc. This method has shown promising results in the NDE of composite panels, honeycomb structures and bond assessment in adhesively bonded structures (Babu Rao \& Baldev Raj 1990). HI technique can be used to investigate the deformation states on the surfaces of pressure vessels. The defects in such components can be differentiated on the basis of their severity. Fringe pattern density is used to find the nature of defects (symmetric or asymmetric etc.). We have used such methodology for the inspection of pressure vessels (Baldev Raj et al 1986). Using this method. the effect of stimuli (!ike load, temperature etc.) can also be assessed. Fabrication and welding processes alter the mechanical properties of the material and introduce residual stresses leading to manifestation of non-uniform deformations. HI technique is well suited to measure these deformations, establish fitness-for-purpose and suggest changes in the manufacturing process and design. $\mathrm{HI}$ has been used to establish accept/reject criterion based on measurement of residual stress introduced during pressure testing in a high energy rate formed stainless steel pressure vessel. Good quality vessels are characterised by small and reasonably uniform deformation fields. On the other hand, poor quality vessels exhibit large local yielding and much greater overall residual strains (Halmshaw 1989). Holographic NDT is particularly useful on complex shapes where other NDE methods such as UT, RT are difficult or time consuming to apply. 
We have developed new methodology employing project interferometry for profiling of stainless steel fuel cladding tubes of fast reactors. Diameter variations of the order of few microns have been reliably measured (Babu Rao et al 1992). This work established the adaptability of this methodology for quality control of tubes towards enhanced structural integrity.

\section{$2.12 X$-ray diffraction technique}

X-ray diffraction (XRD) technique is widely used for measuring residual stresses (RS) in components. RS are generally caused by inhomogeneous plastic strains in a structure. Tensile residual stresses are generally detrimental, increasing the susceptibility of a component to failures due to such causes as fatigue and stress corrosion. On the contrary, compressive residual stresses are usually beneficial, tending to reduce the above susceptibilities (Palanichamy et al 1992b). Thus residual compressive stresses are often deliberately created on the surface. The role of NDE in detecting and assessing residual stresses is ever increasing. NDE techniques that have shown capability include UT, MBN and X-ray diffraction (Palanichamy et al 1992b).

XRD technique measures the interplanar spacing of the lattice to arrive at elastic strains on the surface layers (generally up to 20-30 microns depending on the density) of the material and converts these data into stresses. To find stress, it is not necessary to obtain the separations of the crystallographic lattice planes in the unstressed condition. The X-ray technique can rapidly measure applied and residual stresses on a small area on the surface of polycrystalline materials. This technique is based on the fact that the shift of location of the diffraction profile (also called the peak position) is proportional to the stress value. Thus peak position determination is of fundamental importance in $\mathrm{X}$-ray stress analysis. PC-based systems are now available for reliable and rapid measurement of stresses (Kurita 1987).

We have successfully used this technique to assess residual stress and post weld heat treatment (PWHT) in autogenous butt weld joints of $2 \cdot 25 \mathrm{Cr}-1 \mathrm{Mo}$ steel tubes which will be used in the steam generator assemblies of the prototype fast breeder reactor. The XRD data has shown the nature of stress at the weld centre. XRD technique studies have confirmed that the proposed PWHT at $988 \mathrm{~K}$ for $30 \mathrm{~min}$ is sufficient to remove the residuals stresses (Bhattacharya et al 1992c). This has been further validated by microhardness measurements in weld and parent metal regions. Residual stresses in explosively welded aluminium and stainless steel joints have also been analysed (Rai et al 1993). Residual stress measurements have been carried out on AISI type 304L stainless steel dished ends which failed due to transgranular stress corrosion cracking (Rai et al 1994). Residual stress measurements have also been carried out in another important structural material i.e. carbon steel, using XRD, UT and ABN techniques (Palanichamy et al 1993). The above studies clearly reveal the capability and potential of XRD technique for the assessment of residual stresses in components, an essential information for structural integrity evaluation.

\section{Concluding remarks}

An overview on the capabilities and limitations of various NDT techniques that can be used for the structural integrity of components is discussed. A few case studies related to 


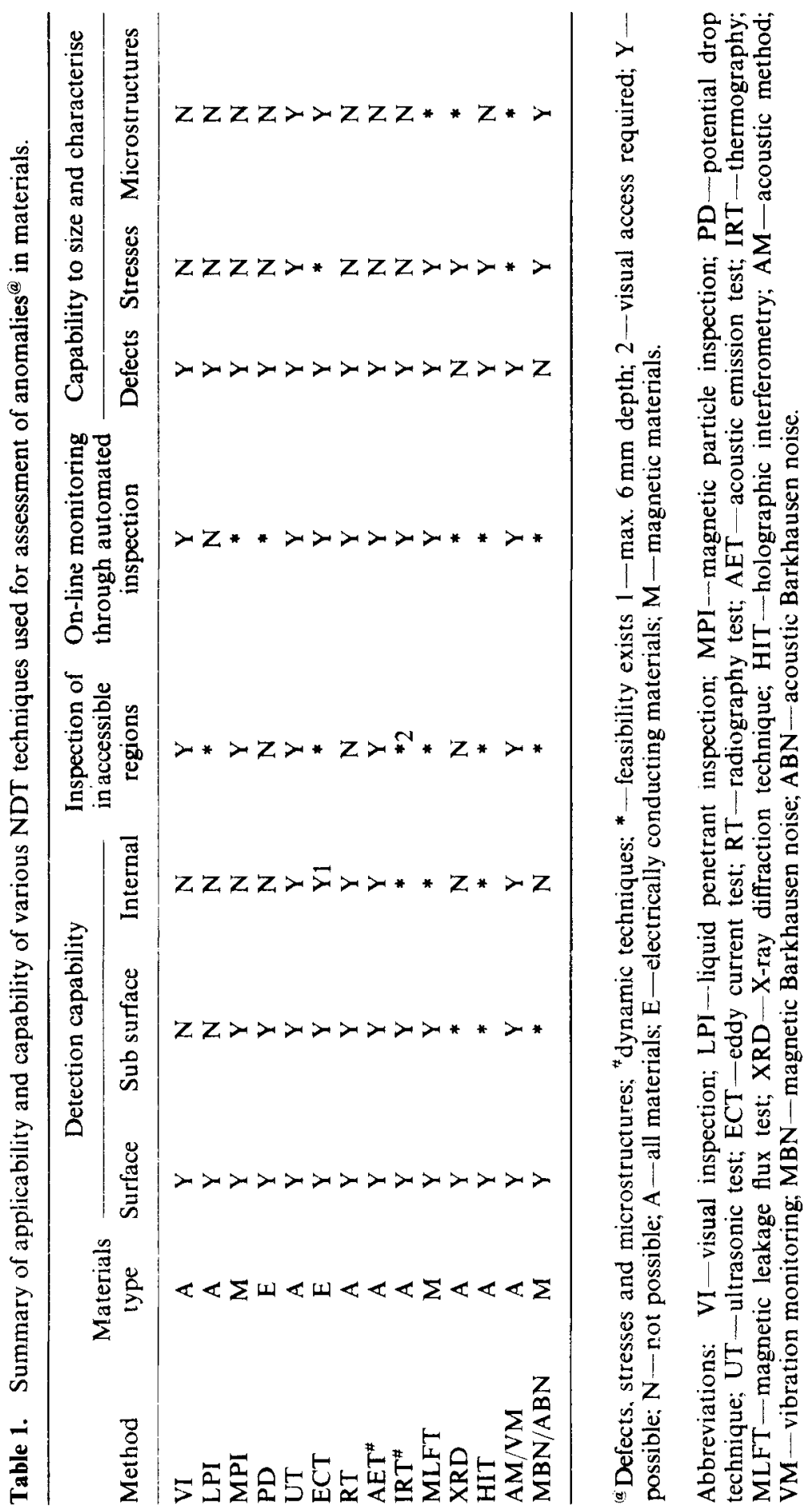


structural integrity based on the investigations carried out by us have been described. The conventional NDT techniques called the big five, viz. magnetic particle, radiography, ultrasonic, eddy current and liquid penetrant techniques can be adapted for many situations. Newer techniques like acoustic emission and thermography are found to be extremely useful and effective for assessment of integrity of components because of their dynamic nature. Table 1 provides information about the capability and applicability of various NDE techniques for the assessment of defects, stresses and microstructural degradations in materials. Improvements in the existing techniques/methodologies and development of new techniques have paved the way for obtaining quantitative information about the anomalies such as defects, stresses and microstructural degradations for easy, sensitive and reliable structural integrity evaluation. A few examples are acoustic microscopy, SAFT, TOFD, eddy current imaging, microtomography, Barkhausen noise analysis (magnetic and acoustic) methods, X-ray stress analysis etc. In recent years, NDT has benefited much with the advent of digital computers, compatible cards and interfacing boards. It is now possible to perform computer modelling to simulate real-life situations to study the interactions between interrogating fields and anomalies. This enables optimised equipment parameters and NDT sensor design for enhancing the sensitivity for anomaly detection. Expert systems, neural network analysis and signal processing and analysis procedures along with the newer NDT procedures provide added impetus to meet the challenges of quality assurance, in-service inspection and failure analysis. However, it is necessary to fully appreciate the capabilities and limitations and the complementary nature of various NDE techniques to enable accurate, reliable and cost-effective inspection.

We wish to thank Dr Placid Rodriguez for his keen interest and constant encouragement during the course of this work.

\section{References}

Arnold W 1990 Tomography of advanced ceramics. Proc. of Indo-German Conf. on Material Characterisation by Non-Destr. Test Techniques (Bombay: BARC)

Babu Rao C, Baldev Raj 1990 Laser techniques in metrology and materials evaluation. Met. Mater. Processes 2: 93-116

Babu Rao C, Vanmathi R, Baldev Raj 1992 Profiling of FBTR clad tubes using projected interferometry. Proc. of laser symposium Madras, pp. 338-339

Baldev Raj 1990 Acoustic emission for characterising deformation and fracture during tensile testing in austenitic stainless steels. PhD dissertation, Indian Institute of Science, Bangalore

Baldev Raj 1992 Looking into future: New techniques in NDT and their potentials. Proc. of National Seminar NDE-92 (eds) C R L Murthy, Baldev Raj, O Prabhakar, A Sreenivasulu (Bangalore: Interline) 1: 23-38

Baldev Raj 1993a Status of NDE research and applications in India. Proc. of the 7th Asia-Pacific Conf. on Non-Destr. Test. Shanghai, China, pp. 18-37

Baldev Raj 1993b Inspection of MAPS II turbine LP rotor. Internal report No. IGC/DPEND/ $93 / 2$

Baldev Raj 1994a Neutron radiography and gaging - an overview. Proc. of First Nat. Workshop on Neutron Radiography and Gauging, Shar, Sriharikota

Baldev Raj 1994b Intelligent processing of materials. Proc. of Conf. on Adv. Non-Destr. Test. Tecniques (Hyderabad: Nuclear Fuel Complex) 
Baldev Raj, Ananthakrishna G, Kalyanasundaram P, Barat P, Jayakumar T 1990a Stimulated amplification of acoustic emission signals during deformation. Scr. Metall. 24: 69-74

Baldev Raj, Babu Rao C, Shyamsunder M T, Venkatraman B, Bhattacharya D K 1986 NDE of pressurised vessel by laser holography. Proc. of National Seminar on Non-Destr. Eval. in Eng. Industry, Coimbatore, D1: 1-5

Baldev Raj, Jayakumar T, Thavasimuthu M 1994a Practical non-destructive testing (to be published)

Baldev Raj, Jayakumar T, Rao B P C 1994b Non-destructive test techniques for assessment of cracks. J. Aeronaut. Soc. India 46: 101-105

Baldev Raj, Kalyanasundaram P, Jayakumar T, Barat P 1989 Influence of grain size on frequency spectra of AE signal generated during tensile deformation in an AISI type 316 stainless steel. J. Acoustic Emission 8: S140-S144

Baldev Raj, Thavasimuthu M, Subramanian C V, Kalyanasundaram P, Rajagopalan C 1992 Utrasonic evaluation of end cap weld joints of PHWR fuel element using signal analysis. Proc. 13th World Conf. on Non-Destr. Test (eds) C Hallai, H Kulscar (Amsterdam: Elsevier) 1: $1065-1070$

Baldev Raj, Venkatraman B 1989 Ionising radiations for non-destructive evaluation. Indian Institute of Radiation Physics, Kalpakkam, Monograph, Chapter ISR P (K)-TD-1

Baldev Raj, Venkatraman B, Babu Rao C $1990 \mathrm{~b}$ An overview of non-destructive applications of thermography. J. Non-Destr. Eval. 10: 1-13

Barat P, Baldev Raj. Bhattacharya D K 1982 A standard procedure for eddy current testing of stainless steel, thin walled nuclear fuel element cladding tubes. Non-Destr. Test Int. 15: 251-255

Beissner R E, Matzkanin G A, Teller C M 1980 New applications of magnetic leakage field methods. NDT Information Analysis Centre, Southwest Research Institute, Texas, Report No. NTIAC-80-1: $1-45$

Bhattacharya D K 1994 Microstructural characterisation of 2-25 Cr-1 Mo steel, $9 \mathrm{Cr}-1$ Mo steel and 17-4PH steel by magnetic Barkhausen noise analysis technique. PhD dissertation, Indian Institute of Science, Bangalore (submitted)

Bhattacharya D K, Jayakumar T, Baldev Raj 1992a Magnetic methods for characterisation of microstructure, creep, fatigue damage and residual stresses. Proc. of National Seminar NDE-92 (eds) C R L Murthy, Baldev Raj, O Prabhahar, A Sreenivasulu (Bangalore: Interline) 1: 110-127

Bhattacharya D K, Jayakumar T, Palanichamy P, Baldev Raj 1993 Microstructural characterisation using ultrasonic velocity and attenuation measurements. Proc. 7 th Asia-Pacific Conf. on Non-Destr. Test. Shanghai, China, pp. 110-126

Bhattacharya D K, Jayakumar T, Vaidyanathan S, Baldev Raj 1992b Magnetic Barkhausen noise analysis for the assessment of microstructures in heat treated $2.25 \mathrm{Cr}-1 \mathrm{Mo}$ and 17-4-PH steel. Proc. 13th Word Conf. on Non-Destr. Test (eds) C Hallai, H Kulscar (Anısterdam: Elsevier) 1: 424-428

Bhattacharya D K, Rai S, Babu Rao C, Vaidyanathan S, Baldev Raj 1992c Assessment of residual stresses and post weld heat treatment in butt weld joints of $2.25 \mathrm{Cr}-1 \mathrm{Mo}$ steel tubes by X-ray diffraction technique and Barkhausen noise analysis. Proc. of National Welding Seminar, Calcutta

Bohn $\mathrm{H}$, Kroning $\mathrm{M}$ et al 1987 Proving the capabilities of the phase array probe/ALOK inspection technique. Nucl. Eng. Des. 102: 361-367

Bray D E, Stanley R K 1989a Non-destructive evaluation-A tool for design, manufacturing and service (New York: McGraw-Hill) pp. 45-301

Bray D E, Stanley R K 1989b Non-destructive evaluation-A tool for design, manufacturing and service (New York: McGraw-Hill) pp. 365-.515

Cielo P, Maldauge X, Deom A A, Lewak R 1987 Thermographic non-destructive evaluation of industrial materials and structures. Mater. Eval. 45: 452-460

Cochran A McNab A, Hayward G 1991 Flaw monitoring using ultrasonic arrays in-situ. Br. J. Non-Destr. Test. 33: 495-505

Collins R, Mirshekar S D, Micheal D H 1984 Surface current distributions around surface flaws in metals. Proc. R. Soc. A393: 159-170

David W L 1981 Some implications of fracture mechanics for non-destructive testing. Proc. of Int. Adv. Non-Destr. Test (New York: Gordon and Breach) 7: 1-11 
Edwards I, Gros X E, Lowden D W, Strachan P 1993 Fusion of non-destructive testing data. Br. J. Non-Destr. Test. 35: 710-713

Field G J, Dunn J T, Cheadle B A 1984 Analysis of the pressure tube failure at pickering ANGS unit 2. AECL-8335, Atomic Energy Canada Limited.

Forster F 1977 Non-destructive inspection of tubing and round billets by means of leakage flux probes. Br. J. Non-Destr. Test 19: 26-32

Halmshaw R 1989 Non-destructive testing 2nd edn (London: Edward Arnold)

Holroyd T J 1986 Practical applications of acoustic emission. Br. J. Non-Destr. Test 28: 224-227

Jayakumar T, Baldev Raj, Willems H 1991 Acoustic methods for characterisation of microstructures and deformation processes in nimonic alloy PE16. Trans. Indian Inst. Met. 44: 327-338

Jayakumar T, Bhattacharya D K, Baldev Raj 1992a Ultrasonic characterisation of metals and alloys. Proc. of National Seminar NDE-92 (eds) C R L Murthy, Baldev Raj, O Prabhakar, A Sreenivasulu (Bangalore: Interline) 1: 128-140

Jayakumar T, Bhattacharya D K, Baldev Raj 1994 Microstructural characterisation by ultrasonic and magnetic methods towards assessment of ageing induced damage in-service. Proc. of Ageing Management of Nucl. Facilities AMNF-94, (Bombay: BARC) S7-S33

Jayakumar T, Bhattacharya D K, Palanichamy P 1993a Ultrasonic attenuation measurements for microstructural characterisation in 17-4 PH steel. J. Non-Destr. Eval. (in press)

Jayakumar T, Bhattacharya D K, Thavasimuthu M, Palanichamy P, Baldev Raj 1993b Ultrasonic measurements for microstructural characterisation in $9 \mathrm{Cr}-1$ Mo steel. Proc. $7 \mathrm{th}$ Asia-Pacific Conf. on Non-Destr. Test., Shanghai, China, pp. 216-222

Jayakumar T, Moorthy V, Bhattacharya D K, Baldev Raj 1992b Acoustic emission studies for leak detection. Proc. of 13th World Conf. on Non-Destr. Test. (eds) C Hallai, H Kulscar (Amsterdam: Elsevier) 1: 50-54

Junger M, Brook C 1990 Beginners guide to principles, sensor selection and evaluation techniques for magnetic flux leakage technique. Br. J. Non-Destr. Test. 32: 513-515

Juva A, Haarvisto M 1977 On the effects of microstructure on the attenuation of ultrasonic waves in austenitic stainless steels. Br. J. Non-Destr. Test. 19: 293-297

Kalyanasundaram P, Baldev Raj, Barat P, Jayakumar T 1989 Reliability of detection of small defects in noisy weldments by advanced signals processing and pattern recognition techniques. Int. J. Pressure Vessels Piping 36: 103-109

Kalyanasundaram P, Baldev Raj, Kasiviswanathan K V, Jayakumar T, Murthy C R L 1992 Leak detection in pressure tubes of pressurised heavy water reactors by AE technique. $B r . J$. Non-Destr. Test. 34: 539-543

Kalyanasundaram P, Rajagopalan C, Baldev Raj, Prabhakar O, Sarma D G R 1991a High sensitivity detection and classification of defects in austenitic weldments using cluster analysis and pattern recognition. Br. J. Non-Destr. Test. 33: 290-297

Kalyanasundaram P, Rajagoplan C, Subramanian C V, Thavasimuthu M, Baldev Raj 1991b Ultrasonic signal analysis for defect characterisation in composite materials Br. J. Non-Destr. Test. 33: 221-226

Kasiviswanathan K V, Venkatraman B, Baldev Raj 1989 Neutron radiography facilities at IGCAR. Proc. of Post Irradiation Examination in Nuclear Programme, (Bombay: BARC) 2: $52-58$

Kasiviswanathan K V, Venugopal V, Baldev Raj 1986 Eddy current studies on stainless steel after mechanical working and thermal annealing. Proc. National Symposium on Metallography and Non-Destr. Test (Bombay: BARC) $1: 9 / \mathrm{g} / 1-9 / \mathrm{g} / 10$

Khanna A S, Jha B B, Baldev Raj 1987 The application of acoustic emission techniques in high temperature oxidation studies. J. Acoustic Emission 4: 209-213

Kilmore R J, Ramachandran S 1989 Remote field eddy current testing of small diameter carbon steel tubes. Mater. Eval. 47: 32-36

Kubiak E J 1968 Infrared detection of fatigue cracks and other near surface defects. Appl. Opt. 7: 1743-1751

Kurita M 1987 A new X-ray method for measuring residual stress and diffraction line broadness and its automation. Non-Destr. Test Int. 20: 277-283

Libby H L. 1971 Introduction to electromagnetic non-destructive test methods (New York: Wiley-Interscience) 
McIntire P, Miller R K 1987 Non-destructive testing handbook. Vol. 5, Acoustic Emission 2nd edn (Am. Soc. Non-Destr. Test.)

McLaughlin P V, McAssey V Deitrich R 1980 Non-destructive examination of fibre composite structure by thermal field technique. Non-Destr. Test Int. 13: 56-64

Mix P E 1987 Introduction to non-destructive testing - A training guide (New York: John Wiley \& Sons)

Moore J F, Tsang S 1977 Non-destructive test methods for the early prediction of fatigue cracks. Proc. Int. Adv. in Non-Destr. Test. (Gordon and Breach Science) 5: 161-173

Mukhopadhyay C K, Kasiviswanathan K V, Jayakumar T, Baldev Raj 1994 Acoustic emission from aging-induced martensite formation in cold worked AISI type 304 stainless steel. Scr. Metall. 30: 303-307

Muller W, Schmitz V, Schafer G 1986 Reconstruction by the synthetic aperture focusing technique. Nucl. Eng. Des. 94: 393-397

Palanichamy P, Joseph A, Bhattacharya D K, Baldev Raj 1992a Non-destructive evaluation of residual stresses in austenitic stainless steel butt weld joints by ultrasonic technique. Proc. of National Welding Seminar

Palanichamy P, Joseph A, Jayakumar T, Bhattacharya D K, Baldev Raj 1992b Residual stresses and their evaluation in welds. Welding engineering handbook (Trichy: Welding Research Institute) 1: 269-296

Palanichamy P, Joseph A, Rai S Bhattacharya D K, Kasiviswanathan K V, Jayakumar T 1993 Non-destructive measurement of residual stresses in carbon steel weld joints. Proc. of National Welding Seminar 39(a)-39(d)

Pelseneer J P, Louis G 1974 Ultrasonic testing of austenitic steel castings and welds. Br. J. Non-Destr. Test. 16: 107-113

Peugeot R S 1982 Theoretical and practical considerations of microfocus radiography. Mater. Eval. 40: $150-152$

Rai S, Babu Rao C, Bhattacharya D K, Baldev Raj 1993 Residual stress measurement of explosively welded Al-SS plates using X-ray diffraction technique Proc. of National seminar NDE-93, Madras.

Rai S, Babu Rao C, Bhattacharya D K, Baldev Raj 1994 Evaluation of residual stresses in AISI 304L stainless steel dished ends. J. Non-Destr. Eval. (in press)

Rajagopalan C, Kalyanasundaram P, Baldev Raj 1992 An expert system for ultrasonic testing of austenitic stainless steel welds Proc. of National Seminar NDE-92 (eds) C R L Murthy, Baldev Raj, O Prabhakar, A Sreenivasulu (Bangalore: Interline) 1: 155-168

Rao B P C, Babu Rao C, Baldev Raj 1993a Modelling of remote field eddy current test phenomenon. J. Non-Destr. Eval. (in press)

Rao B P C, Jayakumar T, Bhattacharya D K, Baldev Raj 1993b New methodology for precise ultrasonic velocity measurements and its applications. J. Pure Appl. Ultrasonics 15: 13-19

Rao B P C, Shyamsunder M T, Babu Rao C, Baldev Raj 1993c Eddy current impedance imaging of surface defects. Proc. 7th Asia-Pacific Conf. on Non-Destr. Test. Shanghai, China pp. 687-693

Rao B P C, Shyamsunder M T, Babu Rao, Bhattacharya D K, Baldev Raj 1992 Computers in eddy current testing. J. Non-Destr. Eval. 12:13-18

Rao B P C, Shyamsunder M T, Bhattacharya D K, Baldev Raj 1989 Multifrequency eddy current inspection of heat exchanger assemblies. Proc. of Seminar on Research in Materials \& Management of Corrosion in Industries, Baroda

Rao B P C, Shyamsunder M T, Bhattacharya D K. Baldev Raj 1990 Optimisation of eddy current probe for detection of garter springs in PHWRs. Nucl. Technol. 90: 389-393

Rao B P C. Shyamsunder M T, Kalyanasundaram P, Bhattacharya D K, Baldev Raj 1991 Development of eddy current test techniques for condition monitoring of pressure tube/calandria tube assemblies of Indian Pressurised Heavy Water Reactors. Br. J. Non-Destr. Test. 33: 437-440

Shyamsunder M T, Rao B P C 1992 Recent advances in eddy current testing Proc. of National Seminar NDE-92 (eds) C R L Murthy, Baldev Raj. O Prabhakar, A Sreenivasulu (Bangalore: Interline) 1: $141-154$

Shyamsunder M T, Rao B P C, Babu Rao C, Bhattacharya D K. Baldev Raj 1993 Partial saturation eddy current inspection of ferromagnetic steam generator tubes Proc. of Naticnal Seminar NDE-93 Mardras 
Shyamsunder M T, Rao B P C, Babu Rao C, Bhattacharya D K, Baldev Raj, 1994 A new tandem probe design for phased-array eddy current testing. Insight 36: 434-436

Silk M G 1984 The use of diffraction-based time of flight measurements to locate and size defects. Br. J. Non-Destr. Test. 26: 208-215

Silk M G, Whapham A G 1989 Living with defects. Br. J. Non-Destr. Test. 31: 307--313

Subramanian C V, Thavasimuthu, Rajagopalan C, Kalyanasundaram P. Bhattacharya D K, Baldev Raj 1991 Development of ultrasonic evaluation methodology for Zircaloy end cap weld joints in thin walled fuel elements for pressurised heavy water reactor. Proc. of National Welding Seminar, Madras 1: 304-311

Szilard J 1982 Ultrasonic testing (New York: Wiley-Interscience)

Temple J A G 1987 Time of flight diffraction technique. Int. J. Pressure Vessels Piping 27: 191-208

Topp D A 1994 Reliable inspection of offshore structures by ACFM technique. Insight 36: $422-425$

University Communique 1987 Br. J. Non-Destr. Test. 29: 28-36

Venkatraman B, Kanmani S, Babu Rao C, Bhattacharya D K, Baldev Raj 1992 In-service inspection of electrical components in atomic power stations by infrared thermographic imaging. Proc. of National Seminar NDE-92 (eds) C R L Murthy, Baldev Raj, O Prabhakar, A Sreenivasulu (Bangalore: Interline) 1: 102-109

Venkatraman B, Kanmani S, Babu Rao C, Bhattacharya D K, Baldev Raj 1993a On-line monitoring of welds by infrared imaging. Proc. 7th Asia-Pacific Conf. on Non-Destr. Test Shanghai, China, pp. 909-916

Venkatraman B, Rajagopal C, Baldev Raj 1993b An expert system to aid radiographic testing. $J$. Non-Destr. Eval. (in press)

Venkatraman B, Sethi V K, Bhattacharya D K 1993c High definition radiography of evaporator welds of steam generator of prototype fast breeder reactor. Proc. of National Welding Seminar 1: 26(a)-26(c)/231-237

Vontz T, Geobbels K, Maisl M, Reiter H, Hireskorn S 1988 Computer aided tomography. Rev. of Progress in Qualitative Non-Destr. Test. (eds) D O Thompson, D E Chimenti (New York: Plenum) 7A: 389-397

Zheng W, Zhu M 1993 A new NDT technique for location of small flaws in small holes. Proc. 7th Asia-Pacific Conf. on Non-Destr. Test. Shanghai, China, pp. 708-713 